\title{
Computer simulations to study interaction between burning rates and pressure variations in confined enclosure fires
}

\author{
F. Bonte ${ }^{1}$, N.Noterman ${ }^{1}$ and B. Merci ${ }^{2}$ \\ ${ }^{1}$ Bel V, subsidiary of the Federal Agency for Nuclear Control, Belgium \\ ${ }^{2}$ Ghent University - UGent, Dept. of Flow, Heat and Combustion Mechanics, Belgium.
}

\begin{abstract}
Fires in nuclear facilities constitute a significant threat to nuclear safety. A major concern when dealing with safety assessments in nuclear facilities is the confinement of nuclear material by dynamic confinement. Therefore, pressure variations within compartments in case of fire are important to consider. This paper focuses on the capability of a zone model (CFAST) and a field model (ISIS) to predict the interaction between mass loss rate and total relative room pressure or oxygen concentration in case of under-ventilated fire conditions. Results are obtained using as input the mass loss rate measured during the experiment and the mass loss rate measured in free atmosphere. A sensitivity study has also been performed for the field model to analyse the influence on the outputs of soot production, radiation modelling, wall emissivity, turbulence modelling and branch flow resistance.
\end{abstract}

\section{$1 \quad$ Introduction}

Fires in nuclear facilities constitute a significant threat to nuclear safety. From the technical point of view, the nuclear facilities design has to consider fires as internal hazard. Since fire scenarios are major contributors to the overall vulnerability of the nuclear installations, large international efforts have been done to understand and analyse the phenomenon of fire and its consequences. In addition, the modelling of fire scenarios within the safety assessment of nuclear installations improved significantly over the last decade. The engineering community has now available tools for the simulation of the fire scenarios. These efforts result in improved nuclear facility design, as well as regulatory requirements to fire safety and fire protection technology. Plant operators are allowed to use fire modelling and fire risk information, along with prescriptive requirements to demonstrate that nuclear power plants can be safely shut down and that radioactive release is minimized in the event of a fire. To achieve this objective, validations of existing fire models and empirical correlations with respect to 
the prediction of parameters of major interest in nuclear facility fire safety and risk analysis are still necessary.

A major concern when dealing with safety assessments in nuclear facilities is the confinement of nuclear material by dynamic confinement (negative pressure system [1]). Therefore, pressure variations within compartments in case of fire are important to consider. Prétrel et al. [2, 6] have already reported on the experimentally observed link between the burning rate and pressure variations inside a compartment during a fire. The present paper focuses on the capability of a zone model (CFAST [3]) and a field model (ISIS, Version 2.3.1 - Incendie SImulé pour la Sûreté [4]) to predict the interaction between mass loss rate and total relative room pressure and oxygen concentration. More precisely, under-ventilated fire conditions are studied.

First of all, the experiments are briefly described. Next, the simulations are presented. The numerical analysis is explained and sensitivity studies are performed, before the conclusions are drawn.

\section{Full-Scale Experiments}

\subsection{Experimental Facility and initial conditions}

Fire experiments are performed in the context of the PRISME (French acronym for "Fire Propagation in Elementary Multi-room scenarios") project in the IRSN DIVA facility (Figure 1), located at the Cadarache site in France [5]. The DIVA facility is included in the JUPITER facility, which has a free volume of $2630 \mathrm{~m}^{3}$. This extensively instrumented facility is specifically dedicated for the performance of fire tests in confined and ventilated multi-room configurations. It comprises three $120 \mathrm{~m}^{3}$ rooms, one $150 \mathrm{~m}^{3}$ corridor, one $170 \mathrm{~m}^{3}$ room on the first floor and a ventilation network. It consists of a $30 \mathrm{~cm}$ thick reinforced concrete structure and equipment is sized to withstand a gas pressure range from $-100 \mathrm{hPa}$ to $520 \mathrm{hPa}$. The doors are made of steel and are leak tight. Control leaks between premises via openings and doors can be made. The following measurements are possible:

- mass loss rate of the fuel;

- pressure,

- temperatures (vertical trees);

- concentration of soot (including size distribution) and gaseous species in each room;

- temperatures and thermal flux densities on the walls;

- pressure, temperatures, flow rates and species concentration at several locations in the ventilation network; 
- velocity profiles at the door if opened;

- and size distribution of soot.

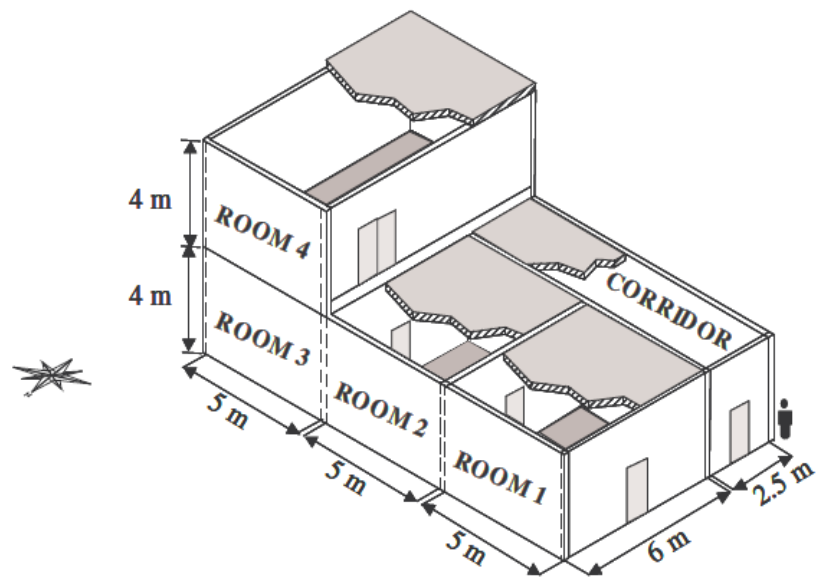

Figure 1: Synopsis of the DIVA facility.

In the present paper, one of the single room tests (PRS-SI-D3, [6]) is investigated. The fire room is Room 2. It is ventilated and closed. Rooms 1 and 3 , both closed and not ventilated, are not used. All the doors to Rooms 1,2 and 3 are airtight and closed with expansion joints. The ceiling is insulated by panels of $5 \mathrm{~cm}$ thick rock wool (THERMIPAN). The actual volume of Room 2 is $118.5 \mathrm{~m}^{3}$. Table 1 gives an overview of the DIVA compartment data. The emissivity of concrete is estimated for clean and smooth walls. When the fire occurs in the compartment, the smoke layer deposits soot on the walls and most probably increases the emissivity of concrete up to 0.8 or 0.9 (maybe more sometimes).

\begin{tabular}{|l|c|l|c|c|}
\hline \multicolumn{4}{|l|}{ DIVA Compartment } & $5 \mathrm{~m} \times 6 \mathrm{~m}$ \\
\hline \multicolumn{2}{|l|}{ Floor Area } & $4 \mathrm{~m}$ & \\
\hline Height & $\begin{array}{c}\text { Heat } \\
\text { conductivity } \mathrm{k} \\
\left(\mathrm{W} . \mathrm{m}^{-1} \cdot \mathrm{K}^{-1}\right)\end{array}$ & $\begin{array}{c}\text { Heat Capacity } \\
\mathrm{Cp}\left(\mathrm{J}_{\mathrm{kg}}{ }^{-1} \mathrm{~K}^{-1}\right)\end{array}$ & Emissivity $\varepsilon$ & $\begin{array}{c}\text { Density } \rho \\
\left(\mathrm{kg} \cdot \mathrm{m}^{-3}\right)\end{array}$ \\
\hline Concrete & 1.5 & 736 & 0.7 & 2430 \\
\hline $\begin{array}{l}\text { Rock Wool } \\
\text { (THERMIPAN) }\end{array}$ & 0.102 & 840 & 0.95 & 140 \\
\hline
\end{tabular}

Table 1: DIVA compartment data and material properties.

The ventilation system includes a blowing branch and an exhaust branch. The exhaust system is equipped with a bank of 8 SOFILTRA type HEPA filters (Figure 2). 


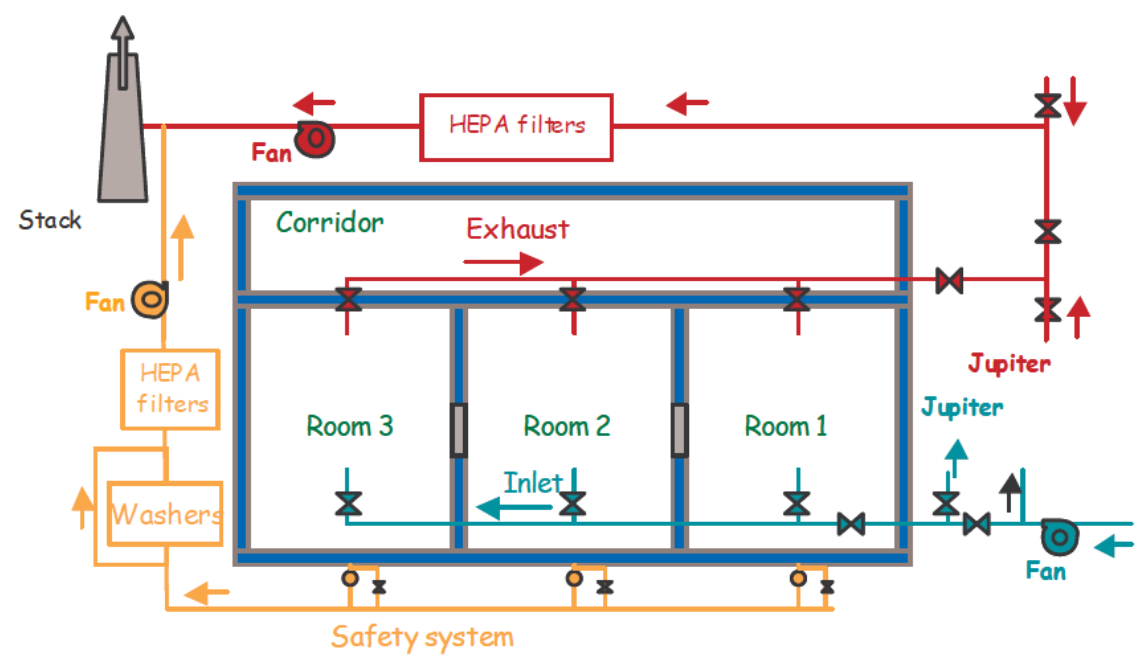

Figure 2: Schematic diagram of the ventilation network.

The intake and exhaust openings of the room consist of rectangular ducts $(0.4 \mathrm{~m} \times 0.4$ $\mathrm{m}$ ) entering into the rooms, $0.75 \mathrm{~m}$ long, for this configuration. The air inlet and outlet openings have a cross section of $0.18 \mathrm{~m}^{2}(0.3 \mathrm{~m} \times 0.6 \mathrm{~m})$ and are equipped with grills. The direction of flow is 'East-West' for both openings.

The data concerning the pressure sensors (location, height ' $\mathrm{H}$ ' and section ' $\mathrm{S}$ ') and the names of the nodes and the branches are specified in Figure 4.

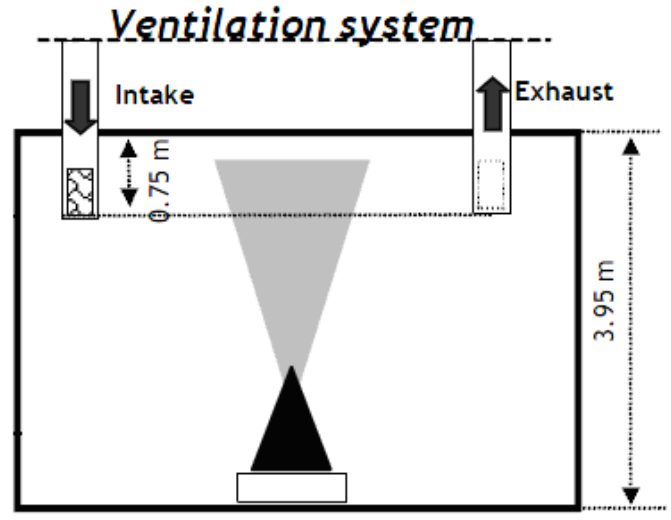

Section of Room 2 (East wall view)

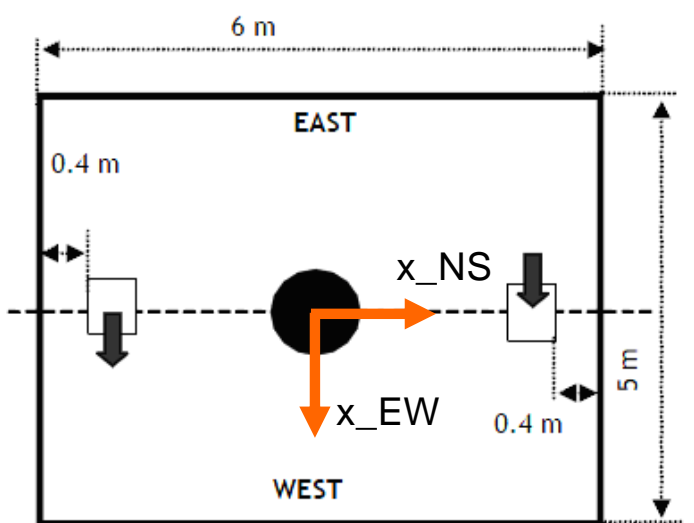

Top view of Room 2

Figure 3: Position of intake and exhaust openings in Room 2.

For the PRS-SI-D3 test, the ventilation system is adjusted to obtain an air renewal rate of $1.5 \mathrm{~h}^{-1}\left(180 \mathrm{~m}^{3} / \mathrm{h}\right)$. The experimental maps for the relative total pressures and the volume flow rates are given in Figure 5. The temperature map is given in Figure 6 . The experimental data are provided "as is" with no assumption. The experimental data presented are some average values between -60 to $0 \mathrm{~s}$ (ignition) for the PRS-SI-D3 test. The density of air is assumed as constant equal at $1.18 \mathrm{~kg} / \mathrm{m}^{3}$ to calculate the 
relative total pressure. The uncertainties concerning the pressure and flow rate measurements were evaluated about $\pm 30 \%[14]$.

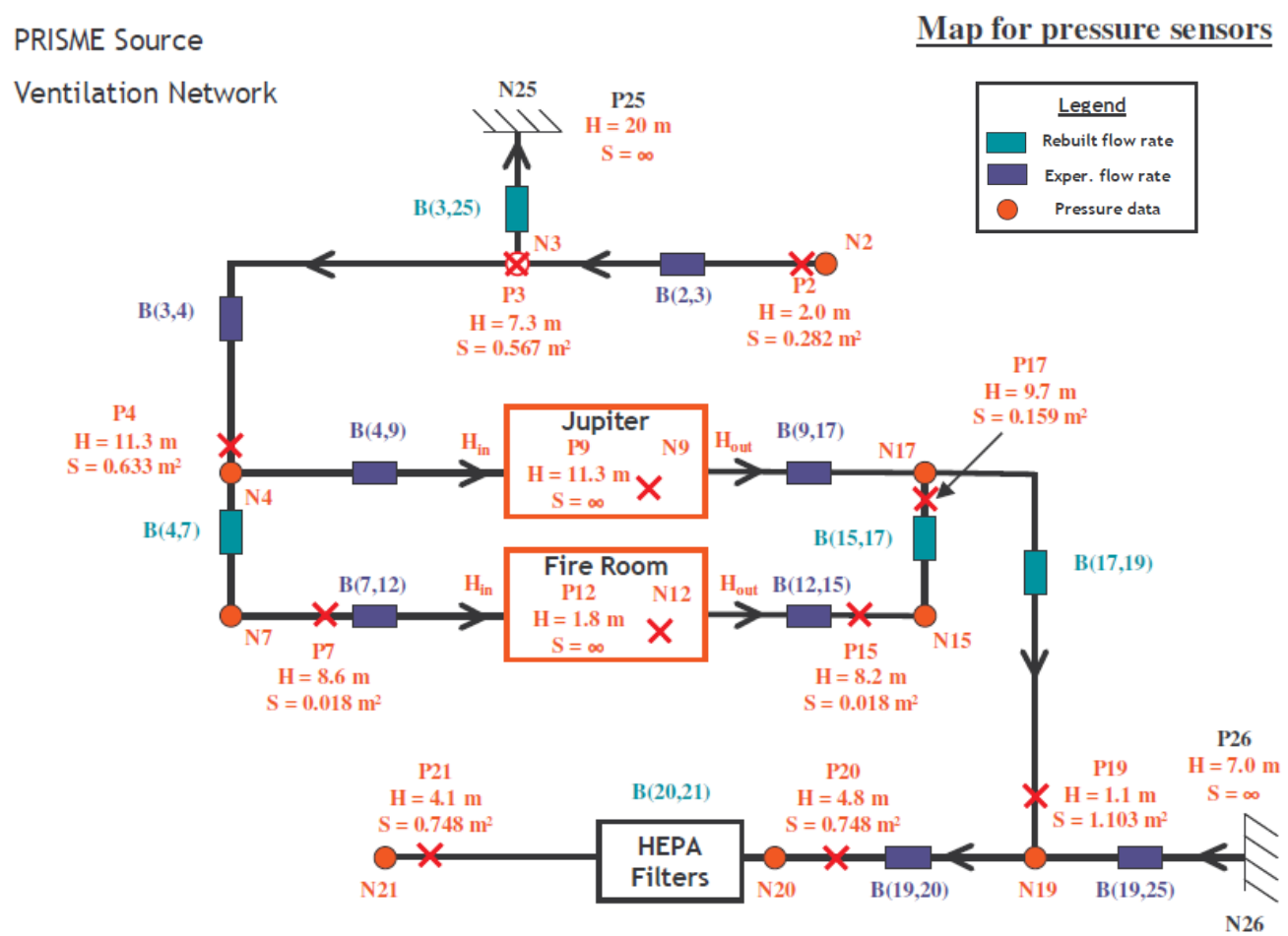

Figure 4: Map for nodes 'N', branches 'B' and pressure sensors 'P' (Courtesy to IRSN).

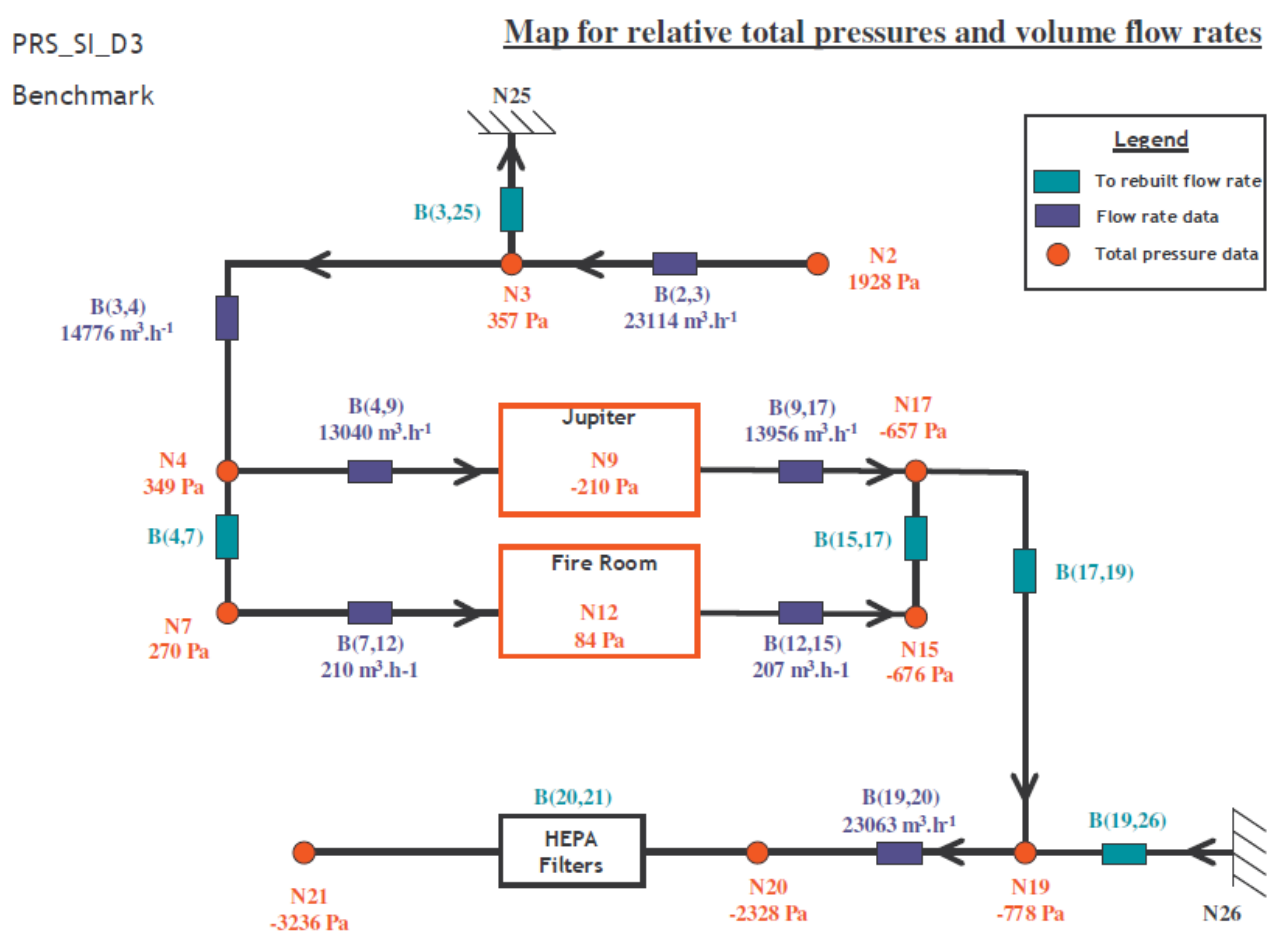

Figure 5: Relative total pressures and air flow rates before ignition (steady state) (Courtesy to IRSN). 


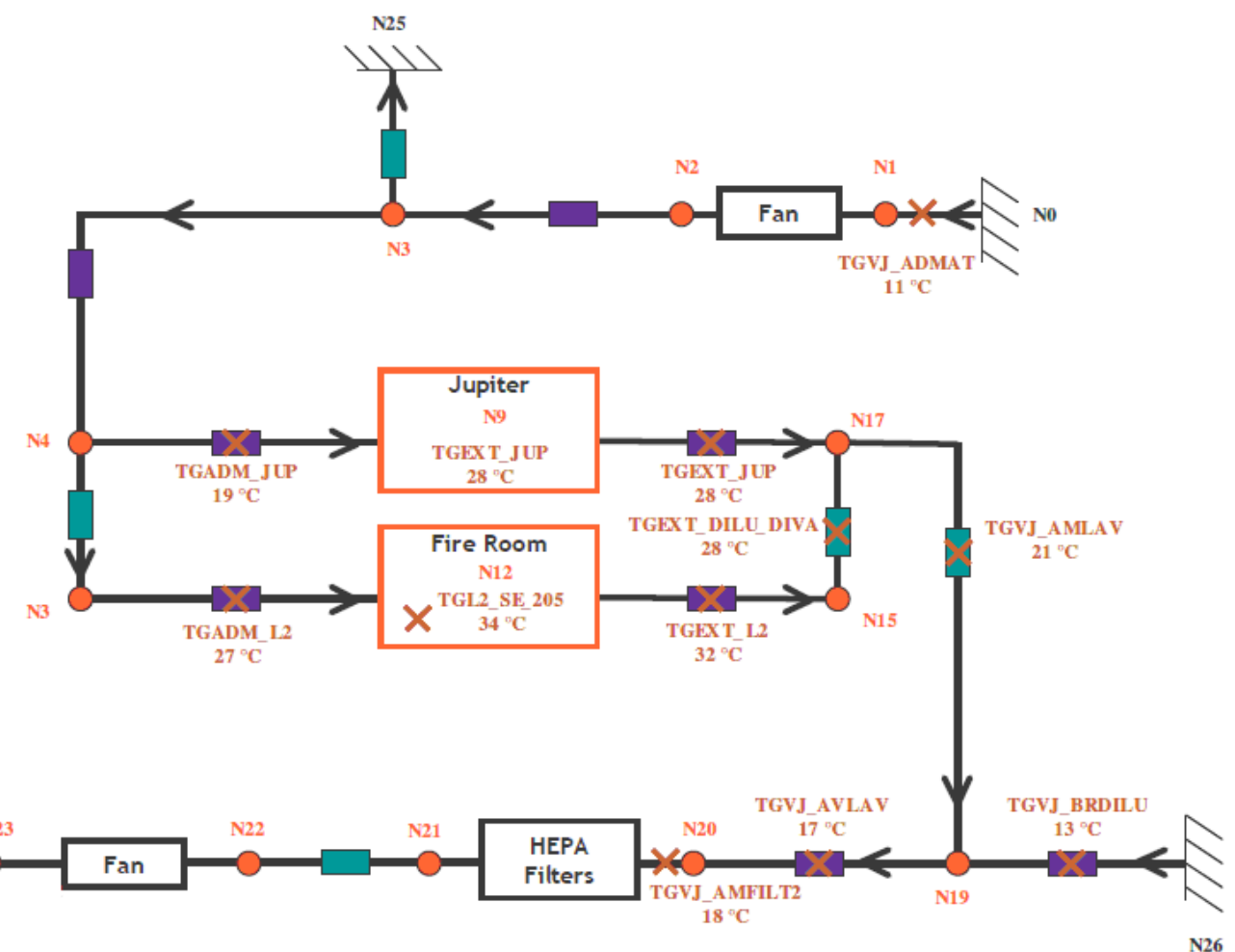

Figure 6: Temperatures before ignition (steady state)

(Courtesy to IRSN).

\subsection{Physical characteristics of the Fire}

A circular hydrogenated tetra-propylene (TPH) pool fire is used to obtain a sooty flame. The $10 \mathrm{~cm}$ deep fuel tank, made of carbon steel ( $5 \mathrm{~mm}$ thick), is placed on a scale. The bottom of the tank is located $0.4 \mathrm{~m}$ above the floor, centred in Room 2 . The pool surface area studied is $0.4 \mathrm{~m}^{2}$. The fuel depth is about $5 \mathrm{~cm}$ prior to ignition. Pool combustion is initiated at ambient temperature by an ignition system consisting of a propane gas burner (approximate power of about $10 \mathrm{~kW}$ ) lit using an electric arc.

\section{$3 \quad$ Numerical simulations}

\subsection{Zone model (CFAST)}

The 'Consolidated Model of Fire and Smoke Transport', CFAST [3], is not intended for detailed study of flow within a compartment. Yet, zone model calculations are very fast and can thus be a useful tool in practice, provided the accuracy of the results is guaranteed. In CFAST, fire is implemented as a source of mass of fuel which is released at a prescribed rate. The combustion products are created while burning and a one-step reaction is assumed for the reaction of fuel and combustion products. Heat 
transfer in walls can be accounted for by solving the heat conduction equation normal to the wall.

The following parameters have been set, in agreement with Figures 5 and 6 :

Ambient Conditions - interior

Gas and wall temperature

$34{ }^{\circ} \mathrm{C}$

Thermodynamic pressure

$98384 \mathrm{~Pa}$

Relative humidity

$50 \%$

Ambient Conditions - exterior

Temperature

$31^{\circ} \mathrm{C}$

Pressure

$98300 \mathrm{~Pa}$

The geometry consists of Room 1, Room 2, Room 3 and the corridor as seen in Figure 1. Room 2 is the fire room. All rooms are modelled because leakages towards these rooms and subsequently towards the outside are included. The walls consist of $0.3 \mathrm{~m}$ thick concrete, the ceiling is $0.05 \mathrm{~m}$ thick THERMIPAN (Table 1) and the floor is concrete with a thickness of $1 \mathrm{~m}$. Surface connections are used for each wall. The rooms have normal flow characteristics; the corridor is modelled as 'default Corridor'. Leakage paths must be specified in compartments with closed doors and windows during the fire event since zone fire models assume that compartments are completely sealed unless otherwise specified. In reality, the resulting pressure and the rate of pressure rise are often kept very small by gas leaks through openings in the walls and cracks around doors, known as "leakage paths." By contrast, compartments with at least one open door or window can maintain pressure close to ambient during the fire event.

All the leakages due to penetrations and cracks have been modelled here as a $0.003 \mathrm{~m}^{2}$ gap $(0.003 \mathrm{~m} \times 1 \mathrm{~m})$ underneath the doors (horizontal flow vents). This gap has been chosen such that the calculated pressure variation matches the experimentally measured value.

The ventilation system is assumed to continue to operate during the fire with no changes brought about by fire-related pressure effects. It is modelled as a constant renewal rate of $180 \mathrm{~m}^{3} / \mathrm{h}$. The description of the fan includes a drop off in flow beginning at a pressure specified at $2000 \mathrm{~Pa}$. Above this pressure drop, the flow gradually drops to zero flow (4000 Pa). CFAST does not include provisions for reverse flow through a fan. The fuel is TPH, a combustible liquid, specified as follows:

Heat of combustion $\Delta H_{c}=4.2 \times 10^{7} \mathrm{~J} / \mathrm{kg}$ 


\begin{tabular}{l|l} 
Heat of Gasification & $361 \mathrm{~kJ} / \mathrm{kg}$ \\
Volatilization temperature & $188^{\circ} \mathrm{C}$ \\
Radiative fraction & 0.35 \\
Molar mass & $0.17 \mathrm{~kg} / \mathrm{m}^{3}$ \\
Total mass & $14.6 \mathrm{~kg}$ \\
$\mathrm{H} / \mathrm{C}$ & 0.1806 \\
$\mathrm{CO} / \mathrm{CO}_{2}$ and $\mathrm{C} / \mathrm{CO}_{2}$ & As in experiment \\
Lower Oxygen Limit & $10 \%$ \\
Gaseous ignition temperature & $53.5^{\circ} \mathrm{C}$ \\
Ignition criterion & Time $=0 \mathrm{~s}$
\end{tabular}

The Mc Caffrey plume model [7] is used.

\subsection{Field model ISIS}

ISIS is an open source CFD (Computational Fluid Dynamics) package developed by IRSN [4]. It is based on the scientific computing development platform PELICANS and available as open-source software (https://gforge.irsn.fr/gf/project/pelicans). It is entirely parallized via this platform, for both the assembly and solution of discrete systems.

The governing equations describing the turbulent reactive flow in low Mach number regime encompass the Favre-averaged Navier-Stokes equations (mass and momentum). Turbulence is modelled by a modified $k-\varepsilon$ model, using the Boussinesq hypothesis for the buoyancy source terms in the transport equations for $k$ and $\varepsilon$ [8]. The EBU model is used for combustion.

The radiative heat transfer equation for an absorbing and emitting medium is solved using the Finite Volume Method [9]. In addition, the effect of soot on the absorption coefficient is taken into account by means of a correlation proposed by Novozhilov [10]. Soot production is modelled on the basis of an average yield, $y_{s}=0.11 \mathrm{~kg} / \mathrm{kg}(\mathrm{kg}$ soot per kg fuel), as measured during the experiment. Soot is transported by convection and diffusion.

An interesting feature concerns the calculation of the thermodynamic pressure in the room. This calculation is based on a simplified momentum balance equation for the system composed of the confined compartment and the ventilation network. A general Bernoulli equation describes each branch i of the network, which is, in this particular case, connected to the compartment (pipe-junction boundary condition): 


$$
\frac{L_{i}}{S_{i}} \frac{\partial Q_{i}}{\partial t}=P_{t h}-P_{n o d e, i}-f
$$

where $L_{i}$ and $S_{i}$ are respectively the length and the cross-sectional area of branch $i, Q_{i}$ is the flow rate in branch $i, P_{\text {node, } i}$ is the pressure at extremity of the branch which is not located at the compartment wall and $f$ is an aerodynamic resistance:

$$
f=\operatorname{sign}\left(Q_{i}\right) R \frac{\left|Q_{i}\right|^{\alpha}}{\rho^{\beta}}
$$

The flow exponents are set to $\alpha=2$ and $\beta=1$.

If the pipe length $L$ is not specified, which is the case here, the stationary Bernoulli equation:

$$
P_{t h}-P_{n o d e, i}=f
$$

is supplemented by the overall mass balance equation of the compartment:

$$
\int_{\Omega} \frac{\partial}{\partial t}\left(\frac{P_{t h} W}{R T}\right)+\sum_{i} Q_{i}=0
$$

Geometric and material properties as used are gathered in the following tables:

\section{- Air properties}

Laminar viscosity

Sutherland viscosity law, $\mu_{0}=1.68 \times 10^{-5}$ Pa.s, $T_{0}=273 \mathrm{~K}, \mathrm{~S}=110.5 \mathrm{~K}$.

Specific heat capacity

$\mathrm{C}_{\mathrm{p}}=1020 \mathrm{~J} /(\mathrm{kg} \cdot \mathrm{K})$

Reference temperature

Turbulent Prandtl

$\mathrm{T}_{\text {ref }}=307 \mathrm{~K}$

$\operatorname{Pr}=0.7$

Density

Turbulent Schmidt

Absorption coefficient

Ideal Gas Law for low Mach number flows $\left(\mathrm{P}_{0}=98384 \mathrm{~Pa}\right)$

Sc $=0.7$

Gas-soot mixture, gas coefficient $0.1 / \mathrm{m}$, soot coefficient $1264 / \mathrm{m} / \mathrm{K}$. Soot density $=1800 \mathrm{~kg} / \mathrm{m}^{3}$

The standard gravity field is applied.

\section{- Fuel properties}

Heat of combustion

Boiling point

$$
\mid \begin{aligned}
& \Delta \mathrm{H}_{\mathrm{c}}=4.2 \times 10^{7} \mathrm{~J} / \mathrm{kg} \\
& \mathrm{T}_{\text {fuel }}=461 \mathrm{~K}
\end{aligned}
$$

The fuel is treated as dodecane with incomplete combustion: $\mathrm{C}_{12} \mathrm{H}_{26}+(18.5-\mathrm{s}) \mathrm{O}_{2}+$ $\mathrm{N}_{2} \rightarrow 13 \mathrm{H}_{2} \mathrm{O}+(12-\mathrm{s}) \mathrm{CO}_{2}+\mathrm{N}_{2}+\mathrm{sC}$ with $\mathrm{s}=1.55833$. $\mathrm{s}$ can be estimated from the data of Tewarson [11] $\left(\mathrm{y}_{\mathrm{s}} \approx 0.15\right)$ or from the experiment $\mathrm{y}_{\mathrm{s}} \approx 0.11 ; \mathrm{y}_{\mathrm{s}}=\mathrm{s}^{*} \mathrm{~W}_{\mathrm{d}} / \mathrm{W}_{\text {fuel }}=$ s*12/170.

\section{- Initial conditions}


Velocity

Gas and wall temperature

Thermodynamic pressure

Turbulence kinetic energy

Dissipation rate of

turbulent kinetic energy

Mixture fraction

Fuel mass fraction
$0.00 .00 .0 \mathrm{~m} / \mathrm{s}$

$\mathrm{T}_{0}=\mathrm{T}_{\text {ref }}=307 \mathrm{~K}$

$\mathrm{P}_{0}=\mathrm{P}_{\text {ref }}+\mathrm{P}_{\text {local }}=98384 \mathrm{~Pa}$

$\mathrm{k}_{0}=1 . \mathrm{E}-6 \mathrm{~m}^{2} / \mathrm{s}^{2}$

$\varepsilon_{0}=1 . \mathrm{E}-9 \mathrm{~m}^{2} / \mathrm{s}^{3}$

0.0

0.0

\section{- Boundary conditions}

At the inlet and exhaust openings, the pipe-junction boundary condition presented above is used. The air flow resistances have been derived from the pressures measured at the extremity of each branch in steady state conditions prior to ignition (see Figure 5 and Figure 6): with $\mathrm{P}_{\text {inlet }}=270 \mathrm{~Pa}\left(\right.$ at $27^{\circ} \mathrm{C}$ ) and $\mathrm{P}_{\text {outlet }}=-676 \mathrm{~Pa}$ (at $32^{\circ} \mathrm{C}$ ), equation (2) yields $R_{\text {inlet }}=46445.1 \mathrm{~m}^{-4}$ and $R_{\text {outlet }}=197142.1 \mathrm{~m}^{-4}$.

With the knowledge of the average branch velocity $u_{\text {inlet }}$, and the setting of the turbulent intensity $i$ and the mixing length scale $I$, the turbulent kinetic energy $k_{\text {inlet }}$ and the dissipation rate of the turbulent kinetic energy $\varepsilon_{\text {inlet }}$ are set at the boundary [12]. The turbulent intensity is set at 0.01 and the mixing length scale to $0.03 \mathrm{~m}$. At the pool surface, the experimentally measured burning rate, $\dot{m}_{c}(t)$, is used to determine the inlet velocity: $\bar{v} \cdot \bar{n}=w_{f u e l}=\frac{\dot{m}_{c}(t)}{\rho_{f u e l} S_{p}}$, along with the following conditions: $\mid \begin{array}{ll}\mathrm{H}=\mathrm{C}_{\mathrm{p}}\left(\mathrm{T}_{\text {fuel }}-\mathrm{T}_{0}\right)+\Delta \mathrm{H}_{\mathrm{c}, \text { eff }}, \mathrm{Y}_{\mathrm{f}}=\mathrm{Z}=1 . & \text { If } \dot{m}_{c}(t)>0 \\ \mathrm{Y}_{\mathrm{f}}=\mathrm{Z}=\mathrm{H}=0 & \text { otherwise }\end{array}$

$\rho=\rho\left(T_{\text {fuel }}\right)=4.14 \mathrm{~kg} / \mathrm{m}^{3}$

Turbulence kinetic energy

Dissipation rate of turbulent kinetic energy

$$
\begin{aligned}
& P_{0}=P_{\text {ref }}+P_{\text {local }}=983 \mathrm{hPa}+P_{\text {local }} \\
& k_{\text {pool }}=1 . E-5 \mathrm{~m}^{2} / \mathrm{s}^{2} \\
& \varepsilon_{\text {pool }}=1 . E-9 \mathrm{~m}^{2} / \mathrm{s}^{3}
\end{aligned}
$$

A gray-surface boundary condition is applied for the radiative intensity, with pool surface emissivity equal to 1 . The fuel inlet temperature is set at boiling temperature $(461 \mathrm{~K})$ and the pool wall is assumed to be adiabatic.

The heat transfer to the concrete walls and THERMIPAN ceiling are calculated with the wall law [18]. The conditions were set as in Table 1, with exception of the emissivity of the concrete wall, which is set to 0.9 . The boundary condition with the exterior is assumed to be adiabatic. The admission and extraction ventilation branches are modelled as adiabatic. 


\section{- Mesh characteristics and grid convergence}

Grid sensitivity is important in the verification process of the numerical simulation results. The grid convergence for a certain quantity can be influenced by the choice of the time step and discretization schemes [13]. Therefore, a number of mesh/time step studies have been performed, confirming that the grid is adequate (successive reductions in mesh cell size hardly modify the results under consideration). Table 2 summarizes the grid characteristics while Figure 7 provides a graphical impression.

\begin{tabular}{|c|c|c|c|c|c|}
\hline Name & $\mathrm{N}_{\text {cells }}$ & $\Delta \mathrm{x}_{\text {pool }} \Delta \mathrm{y}_{\text {pool }} \Delta \mathrm{z}_{\text {pool }}$ & $\Delta \mathrm{x}_{\max } \Delta \mathrm{y}_{\max } \Delta \mathrm{z}_{\max }$ & $\begin{array}{l}\Delta \mathrm{x}_{\text {wall }}, \\
\Delta \mathrm{y}_{\text {wall }}\end{array}$ & $\Delta \mathrm{z}_{\text {ceiling }}$ \\
\hline M6 & $\begin{array}{l}46 \times 56 \times 40 \\
=103040\end{array}$ & $4.0 \times 4.0 \times 5.7$ & $18.8 \times 18.8 \times 14.3$ & $6 \rightarrow 18$ & $6 \rightarrow 9$ \\
\hline
\end{tabular}

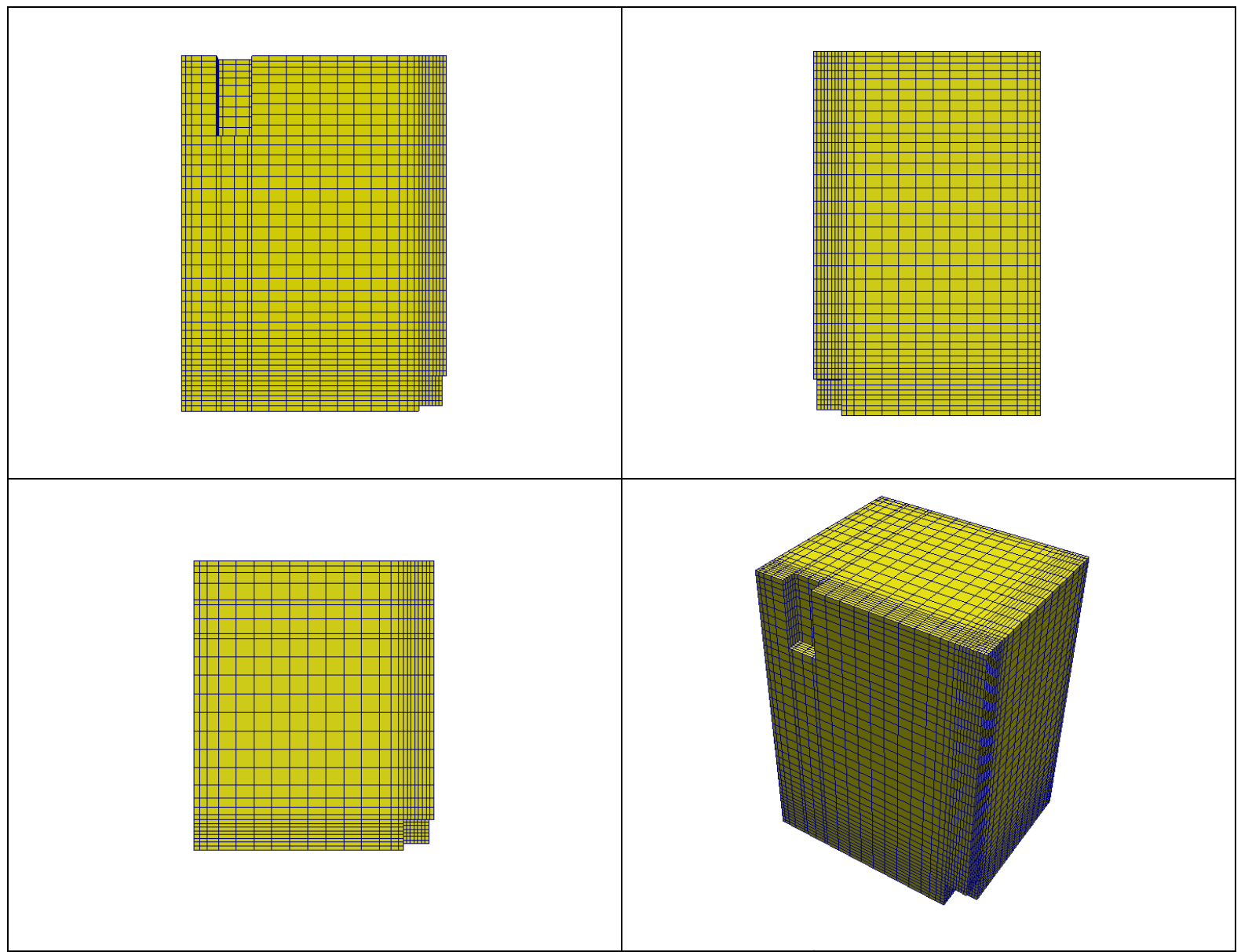

Figure $7 ;+x \_N S,+x \_E W,+Z$ and $3 D$ mesh clips. Only $1 / 4^{\text {th }}$ of the symmetrical mesh is shown. 
In order to quantify differences between model predictions and experimental measurements, much effort has recently been carried out to develop the application of metric operators. The reader is referred to a PRISME group publication [14], where a discussion is given on several metric operators for the case of a pool fire scenario in a well-confined compartment.

The simplest option is the single-point comparison, which can be used to quantify differences between measurements and numerical results for (scalar) quantities that are independent of time and space, or to compare point wise peak values from fire experiments and model predictions:

$$
\varepsilon=\frac{M-E}{E}
$$

where $\mathrm{E}$ represents the experimental observation and $\mathrm{M}$ the model prediction. A normalized relative difference can be used [15] if one wants to take into account the initial state of the calculation as a reference state or to avoid any discussion about units:

$$
\varepsilon=\frac{\Delta M-\Delta E}{\Delta E}=\frac{\left(M_{p}-M_{0}\right)-\left(E_{p}-E_{0}\right)}{\left(E_{p}-E_{0}\right)}
$$

where $\Delta M$ is the difference between the peak value $\left(M_{p}\right)$ of the model prediction and the ambient value $\left(\mathrm{M}_{0}\right)$, and $\Delta \mathrm{E}$ is the difference between the experimental observation $\left(E_{p}\right)$ and the ambient value $\left(E_{0}\right)$.

A general formulation for the single-point comparison using peak values (e.g. temperature, over- or under-pressure, critical oxygen value in the compartment, etc.), named Local Error, can be written as:

$$
\varepsilon=\frac{\max \left(\Delta m_{i}\right)-\max \left(\Delta e_{i}\right)}{\max \left(\Delta e_{i}\right)} \text { or } \varepsilon=\frac{\min \left(\Delta m_{i}\right)-\min \left(\Delta e_{i}\right)}{\min \left(\Delta e_{i}\right)}
$$

where $\Delta \mathrm{m}_{\mathrm{i}}=\mathrm{m}_{\mathrm{i}}-\mathrm{m}_{0}$ and $\Delta \mathrm{e}_{\mathrm{i}}=\mathrm{e}_{\mathrm{i}}-\mathrm{e}_{0}$ with $\mathrm{m}_{\mathrm{i}}$ and $\mathrm{e}_{\mathrm{i}}$ the $\mathrm{i}^{\mathrm{th}}$ values of the vector $\bar{m}$ and $\bar{e}$ respectively.

In order to obtain an overall comparison of two curves, the single-point comparison can be extended to multiple points. Each of these curves can be represented as a multidimensional vector, with each point in time defining an additional dimension. For simplicity, the analysis presented treats time-dependent quantities either averaged in space or measured at a point. Prior to quantification of the differences, the data is interpolated to a common time discretization (here $4 \mathrm{~s}$ was used). The difference in the overall magnitude of two vectors is calculated by the normalized Euclidean distance between two vectors, termed Global Error: 


$$
\varepsilon=\frac{\|\vec{m}-\vec{E}\|}{\|\vec{E}\|}=\sqrt{\frac{\sum_{i=1}^{n}\left(m_{i}-E_{i}\right)^{2}}{\sum_{i=1}^{n}\left(E_{i}\right)^{2}}}
$$

If the Euclidean Distance is zero, both vectors are identical.

To compare the shapes of the two curves, the cosine of the normalized inner product of the vectors $E$ and $M$ is calculated.

$$
\cos [\angle(\vec{x}, \vec{y})]=\frac{\langle\vec{x}, \vec{y}\rangle}{\|\vec{x}\|\|\vec{y}\|}
$$

When the cosine equals 1 , both curves can differ from each other only by a constant multiplier.

Below, the results are evaluated using these three quantities.

\section{$5 \quad$ Numerical simulation results: discussion}

\subsection{Burning Rate}

As first part of the code testing, results in circumstances of oxygen deficiency are investigated. The burning rate is an important boundary condition of the problem. One option is to impose the burning rate as measured in the experiments. This curve is labelled 'MLR-exp' in Figure 8. Results with this curve as input are labelled 'MLRexp' below.

Another option is to consider the mass-loss-rate (MLR) curve as determined in a free atmosphere as input. This is common practice in calculations by fire safety engineers, implicitly assuming that the model in the simulations will deal with circumstances of oxygen deficiency and radiative feedback effects towards the flaming region. The input curve is labelled 'MLR-exp-free-atm' in Figure 8. Results with this curve as input are labelled 'MLR-exp-free-atm' below.

The burning rate evolution in the confined ventilated compartment versus time follows the curve in free atmosphere quite well during the first three minutes. After about 200s, the burning rate becomes higher in the compartment than in free atmosphere, most probably due to radiative heat feedback from the flames to the fuel. After 5 minutes, the fire starts to extinguish. Complete extinction is achieved after about 6 minutes.

- ISIS

With the version of ISIS used here, however, solely the effect of oxygen deficiency on the mass loss rate can be taken into account, using the Peatross - Beyler correlation [16]: 


$$
\dot{m}=\dot{m}_{0}\left(10 X_{O_{2}}-1.1\right)
$$

with $\dot{m}_{0}$ the burning rate $(\mathrm{kg} / \mathrm{s})$ for a fire in 21 vol\% oxygen concentration and $\mathrm{X}_{\mathrm{O} 2}$ the mean oxygen mole fraction in a region near the flame. The region for averaging the oxygen molar fraction $\mathrm{X}_{\mathrm{O} 2}$ was chosen as a cube of $1 \mathrm{~m}^{2}$ surface area and $0.4 \mathrm{~m}$ height around the burner. Averaging the oxygen mole fraction over a larger volume (e.g. the 'whole domain') negatively affects the results.

Expression (10) cannot predict a higher burning rate within the compartment than in free atmosphere. Therefore, the observation in the period 200s - 300s cannot be captured. This is clearly seen in Figure 8: the evolution is almost perfect during the first 200s. After that, the MLR-exp curve cannot be followed. For obvious reasons, burning afterwards (after 360s) lasts longer than in the MLR-exp curve, since the fuel is consumed less rapidly. Despite this deficiency, the free atmosphere burning rate as input, in combination with the Peatross - Beyler ('PB') correlation (10), is used in the following sections.

Incorporation of effects of both lack of oxygen and radiative feedback is work-inprogress [17], but this is beyond the scope of the present paper.

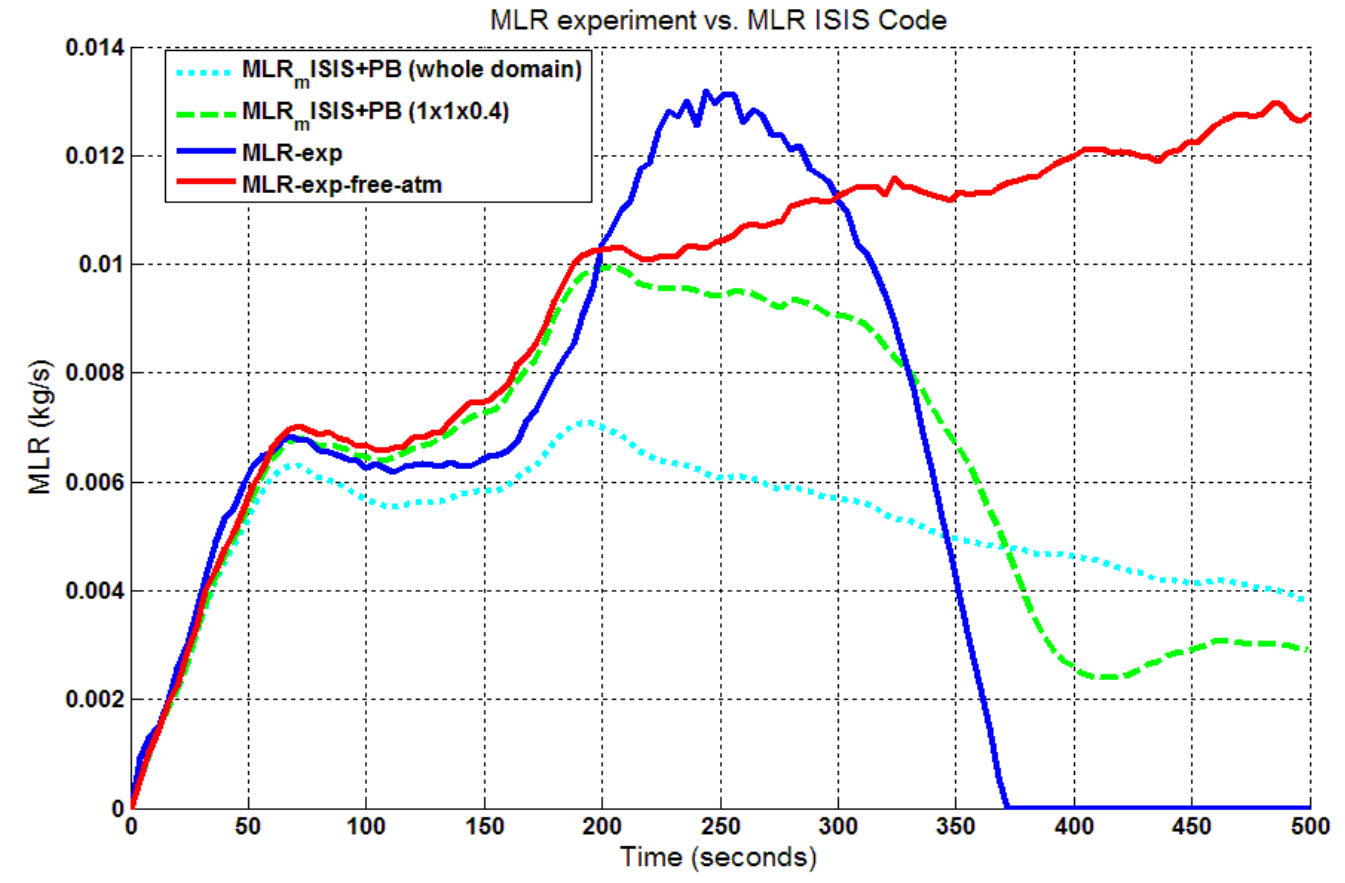

Figure 8: Measured burning rate in the compartment ('MLR-exp') or in free atmosphere ('MLR-exp-free-atm') and calculated from ISIS ('near flame region' either a cube of $1 \times 1 \times 0.4 \mathrm{~m}^{3}$ or 'whole domain'). Input for the simulations is 'MLR-exp-free-atm'.

\section{- CFAST}

Fires in CFAST are defined as a series of individual fire objects which are then placed as desired within compartments in the simulation. Each fire object defines the time 
dependent variables of the fire which are the mass loss rate, rate of heat release, fuel height, and fuel area. In the CFAST model, if sufficient oxygen is available, then fuel is fully burned as [3]:

$$
\dot{m}=\dot{m}_{O, \text { actual }} x \frac{E}{\Delta H_{C}}
$$

Where $E$ is the heat release per mass unit of oxygen consumed, taken to be $1.31 \times 10^{7}$ $\mathrm{J} / \mathrm{kg}$ (based on oxygen consumption calorimetry for typical fuels) and $\dot{m}_{O \text {,actual }}=\dot{m}_{O, \text { needed }}$, the oxygen needed to achieve full combustion.

However, if the oxygen concentration is low enough, a limit of burning due to oxygen depletion is incorporated by limiting the burning rate as the oxygen level decreases until a "lower oxygen limit" (LOL) is reached. To limit the actual burning which takes place in the combustion zone, the following model is incorporated:

$$
\dot{m}_{O, \text { actual }}=\min \left\{\dot{m}_{O, \text { needed }}, \dot{m}_{O, \text { available }}\right\}
$$

The lower oxygen limit is incorporated through a smooth decrease in the burning rate near the limit:

$$
\dot{m}_{\text {, available }}=\dot{m}_{e} X_{O_{2}} C_{L O L}
$$

where $\dot{m}_{e}$ is the mass entrainment flow rate, $\mathrm{X}_{\mathrm{O} 2}$ is the mass fraction of oxygen, and the lower oxygen limit coefficient, $\mathrm{C}_{\mathrm{LO}}$, is the fraction of the available fuel which can be burned with the available oxygen and varies from 0 at the limit to 1 above the limit. By concept, $\dot{m}_{e}$ and $\mathrm{X}_{\mathrm{O} 2}$ are calculated for each zone in CFAST, i.e. the lower layer, the upper layer and the vent flow. In each zone, the heat release, originating from the pyrolysis rate of the source or unburned hydrocarbons of previous regions, is limited by the available oxygen in that region.

The curve labelled 'MLR $\mathrm{m}_{\mathrm{m}}$ CFAST-free-atm+LOL12' in Figure 9 shows the effect of using a lower oxygen value of $12 \%$ on the MLR-exp-free-atm input. At a time of 5.3 minutes, the oxygen drops below $12 \%$ and the MLR is consequently lowered.

The investigation of altering the LOL value is shown in Figure 9. If a very low LOL value is used (e.g. 1\%, i.e. 'LOL1'), the input curve of MLR will be tracked unaltered by CFAST. Because it is desired that the MLR-exp stays unaffected (it is a measured value inside the compartment), a LOL of $1 \%$ is further used. A LOL of $10 \%$ or $12 \%$ seems adequate to be used with MLR-exp-free-atm due to the fact that these values produce the lowest Global Error and best Cosine values (Figure 10) for the MLR prediction. With a LOL of $14 \%$, the MLR drops too soon.

When the simulations reach the lower oxygen limit, the burning rate is limited as described above. Due to this lowering of burning rate, the loss of heat becomes larger 
than the addition of heat, leading to the lowering of pressure. In turn, the admission of fresh air is possible again, leading to a disturbance (uppercut) in mass loss rate for the CFAST simulations.

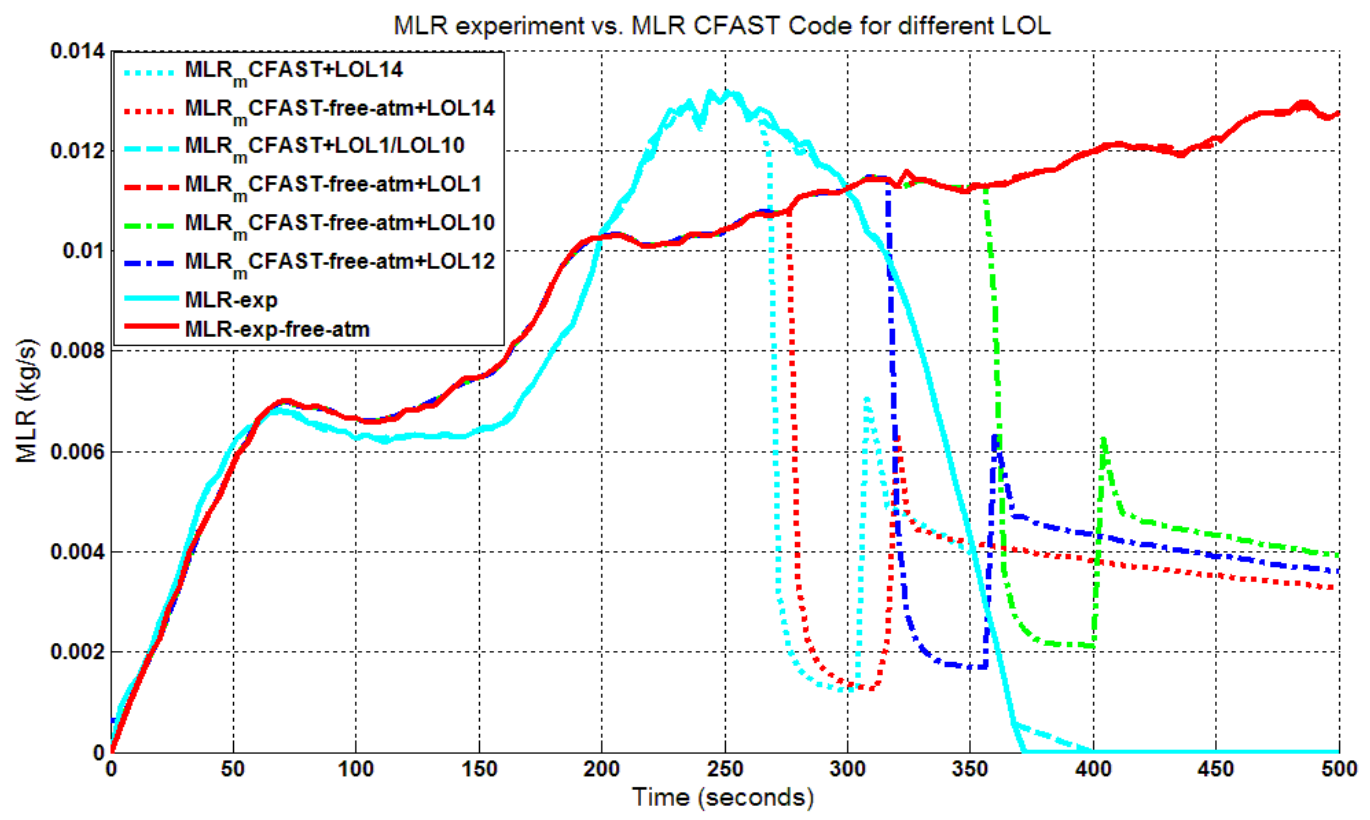

Figure 9: Measured burning rate in the compartment ('MLR-exp') or in free atmosphere ('MLR-exp-free-atm') and calculated from CFAST for different LOL. (MLR-exp-free-atm overwritten with $M L R_{m}$ CFAST-free-atm+LOL1).

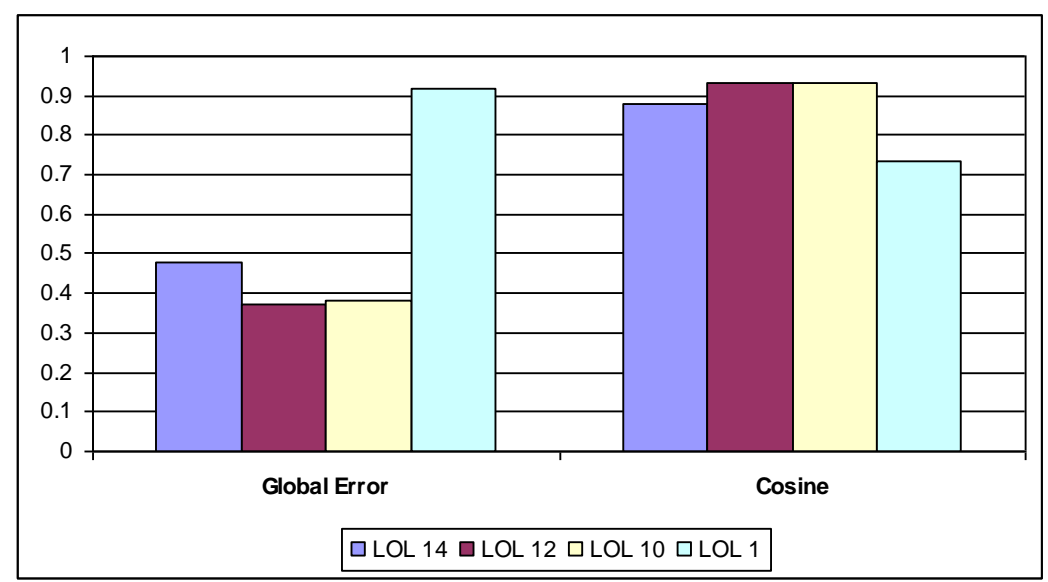

Figure 10: Global Error and Cosine (0-500s) for different LOL in CFAST (MLR-exp-free-atm response).

For completeness, the quantitative comparison of above mentioned simulation results is shown in Table 3. The Local and Global Errors and the Cosine of the angle between the vectors are reported for the MLR responses of the simulations with 'MLR-exp-freeatm' as input.

In the following sections, the 'MLR ${ }_{m}$ CFAST+LOL1' is used in CFAST in case of analysis based on the mass loss rate as measured inside the compartment (can be shortened 'MLR-exp' as it is basically the same). In ISIS, no Peatross \& Beyler 
correlation is used in this case. This choice is made when it is desired that both codes track unaffected the MLR-exp curve as measured inside the compartment.

\begin{tabular}{|l|c|c|c|c|c|c|}
\hline & \multicolumn{3}{|c|}{$\begin{array}{c}\text { ISIS + Peatross - } \\
\text { Beyler (1x1x0.4) }\end{array}$} & \multicolumn{3}{c|}{ CFAST + LOL 12\% } \\
\hline $\begin{array}{l}\text { Time } \\
\text { frame (s) }\end{array}$ & $\begin{array}{c}\text { Local } \\
\text { Error }\end{array}$ & $\begin{array}{c}\text { Global } \\
\text { Error }\end{array}$ & cosine & $\begin{array}{c}\text { Local } \\
\text { Error }\end{array}$ & $\begin{array}{c}\text { Global } \\
\text { Error }\end{array}$ & cosine \\
\hline $0-100$ & -0.00 & 0.07 & 0.998 & 0.02 & 0.06 & 0.998 \\
\hline $100-250$ & -0.25 & 0.18 & 0.985 & -0.22 & 0.16 & 0.988 \\
\hline $250-450$ & & 0.37 & 0.930 & & 0.48 & 0.881 \\
\hline $0-500$ & -0.25 & 0.30 & 0.953 & -0.13 & 0.37 & 0.930 \\
\hline
\end{tabular}

Table 3: Quantitative comparison for MLR responses by the code with the mass-lossrate (MLR) curve as determined in a free atmosphere 'MLR-exp-free-atm' as input. Local Errors are determined for the maximum values of the curves.

\subsection{Total derivative room pressure and the ventilation flow rate}

Room pressure may be important when it contributes to smoke migration to adjacent compartments. It is also a major concern when dealing with dynamic confinement to minimize the contamination propagation in nuclear facilities. Together with the total relative pressure, volume flow rate at the admission and extraction branches of the ventilation network describe the aeraulic behaviour of the fire room and the effects on the ventilation network during the fire. These attributes can also be important because it influences the outcome of under ventilated fires. Both CFAST and ISIS calculate room pressure as they solve energy and mass balance equations in the control volume. CFAST requires the volume flow rate at the branches as an input. A change in flow rate can be defined in CFAST with a description of a fan or the change of the initial opening fraction of a mechanical vent at a certain time during the simulation. CFAST does not include provisions for reverse flow through a fan. The ISIS model provides a boundary condition which can be used in the case of a confined compartment connected to a ventilation network (section 3.2). The particular modelling takes into account pressure variations over time inside the fire compartment.

\section{- ISIS}

Figure 11 shows the measured versus predicted pressures in time by ISIS. The measured pressure has an expanded uncertainty of $\pm 2 \%$ [14]. ISIS predicts the pressure behaviour very well with MLR-exp as an input. The reproduction of pressure variations are important for the nuclear safety and are qualitatively recovered by ISIS. 


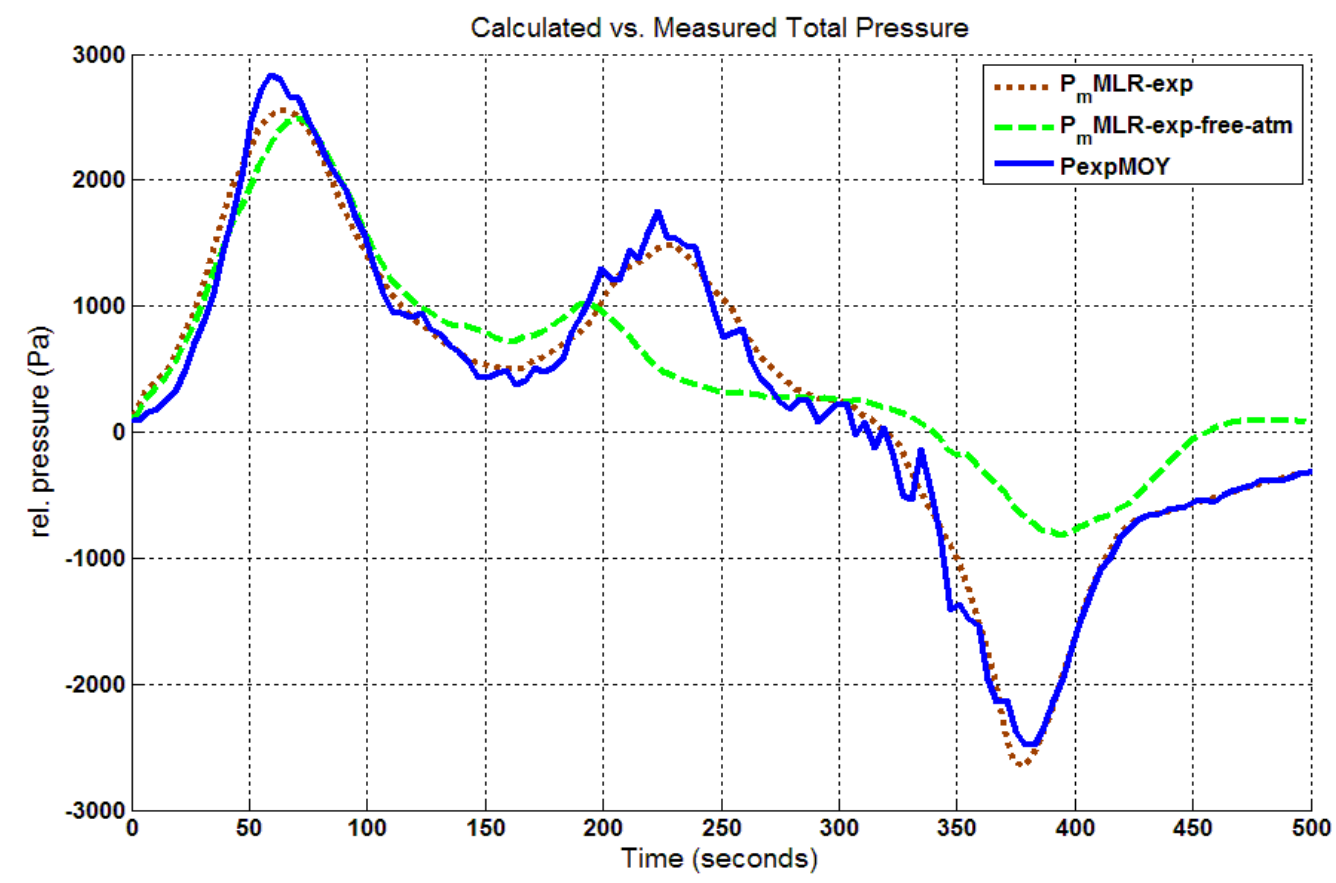

Figure 11: Calculated vs measured total relative pressure in the fire room (measuring range: $-7000 \ldots 10000 \mathrm{~Pa}$ ). $X_{m}=$ ISIS prediction

Further, roughly no difference in pressure prediction is observed during the first 200s due to the consistent MLR-exp and MLR-exp-free-atm. Between 200s and 320s, MLRexp-free-atm is smaller, resulting in less pressure rise (due to less heating). When applying the MLR-exp-free-atm, the fire keeps on burning after 370 s because the code does not predict the extinguishment. As a result, heating still occurs, resulting in a higher pressure than when applying MLR-exp. These effects are also visible in the quantitative comparison (Table 4). The errors between measured and calculated pressure rise with time for MLR-exp-free-atm as input. This shows that the MLR greatly affects the pressure behaviour inside the compartment.

Additionally, the above shows that it is important to consider the extinction phase of a fire and the cooling down of the compartment within the safety analyses concerning pressure confinements. In general, the occurring negative pressure can be explained due to the larger loss of heat through the walls and vents than the heat generated by the fire in the compartment.

In order to validate the ISIS pipe-junction boundary condition, considerations of pressure and volume flow rate at the admission and extraction branches of the ventilation network are regarded (Figure 12). As could be expected, errors for volume flow rate (Table 5 and Table 6) are larger for MLR-exp-free-atm than for MLR-exp because of the larger error for MLR-exp-free-atm (0-500s). A differentiation in errors can be noticed between the prediction of the volume flow at admission and extraction 
branch. Before extinguishing of the fire, the Global Error is smaller for the extraction. The comparison for the extraction volume flow rate has even so a Cosine value closer to 1 , resulting in a better performance of the boundary condition for the extraction. The somewhat to high predicted reverse flow through the admission seems to cause the small under prediction of the first and second pressure peak (Table 4). Nonetheless, the results evidence the used boundary condition is capable of modelling the in- en outlet branch.

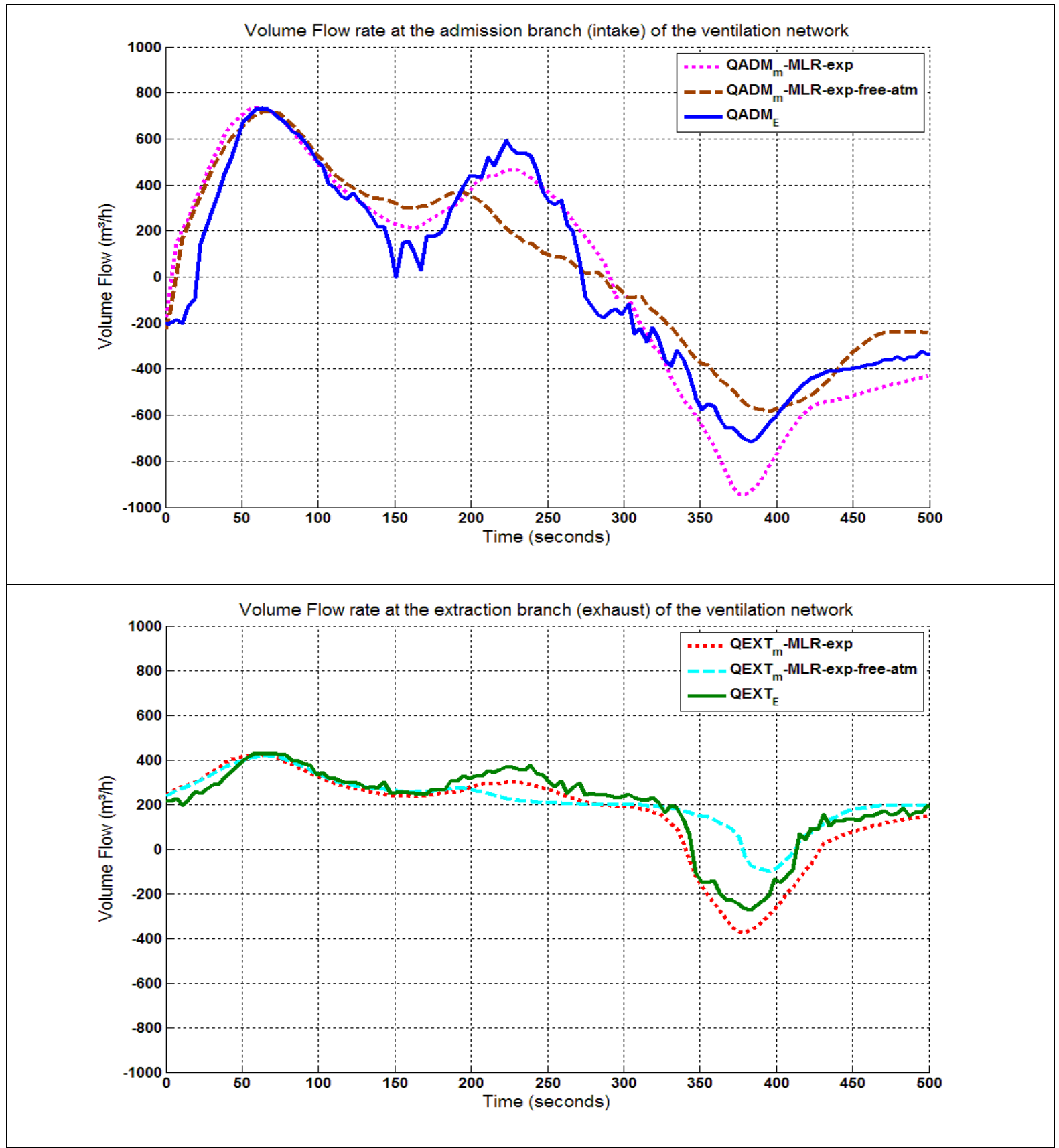

Figure $12 \mathrm{a}$ and $\mathrm{b}$ : Calculated vs. measured ( $\pm 10 \%)$ volume flow rate at the admission (a) and extraction branch (b) of the ventilation network; $X_{m}=$ ISIS prediction, $X_{E}=$ experiment. 


\begin{tabular}{|l|c|c|c|c|c|c|c|c|}
\hline \multirow{2}{*}{ PRESSURE } & \multicolumn{4}{|c|}{ ISIS } & \multicolumn{3}{c|}{ ISIS + Peatross - Beyler } \\
MLR-exp & \multicolumn{4}{|c|}{ (1x1x0.4) MLR-exp-free-atm } \\
\hline $\begin{array}{l}\text { Time frame } \\
(s)\end{array}$ & \multicolumn{2}{|c|}{ Local Error } & $\begin{array}{c}\text { Global } \\
\text { Error }\end{array}$ & cosine & Local Error & $\begin{array}{c}\text { Global } \\
\text { Error }\end{array}$ & cosine \\
\hline $0-100$ & Max & -0.10 & 0.10 & 0.995 & Max & -0.12 & 0.13 & 0.993 \\
\hline $100-250$ & Max & -0.15 & 0.13 & 0.992 & Max & -0.16 & 0.53 & 0.850 \\
\hline $250-450$ & Min & 0.07 & 0.15 & 0.988 & Min & -0.67 & 0.72 & 0.854 \\
\hline $0-500$ & & & 0.13 & 0.992 & & & 0.51 & 0.868 \\
\hline
\end{tabular}

Table 4: Quantitative comparison for PRESSURE between experimental data and the response by the ISIS code with the MLR curve 'MLR-exp' or 'MLR-exp-free-atm' as input.

\begin{tabular}{|c|c|c|c|c|c|c|c|c|}
\hline \multirow{2}{*}{$\begin{array}{l}\text { Q-ADM } \\
\\
\text { Time } \\
\text { frame } \\
\text { (s) }\end{array}$} & \multicolumn{4}{|c|}{$\begin{array}{c}\text { ISIS } \\
\text { MLR-exp }\end{array}$} & \multicolumn{4}{|c|}{$\begin{array}{c}\text { ISIS + Peatross - Beyler } \\
(1 \times 1 \times 0.4) \text { MLR-exp-free- } \\
\text { atm }\end{array}$} \\
\hline & Loca & Error & $\begin{array}{l}\text { Global } \\
\text { Error }\end{array}$ & cosine & Loca & Error & $\begin{array}{c}\text { Global } \\
\text { Error }\end{array}$ & cosine \\
\hline $0-100$ & Max & 0.00 & 0.36 & 0.944 & $\operatorname{Max}$ & -0.02 & 0.30 & 0.958 \\
\hline $100-250$ & Max & -0.21 & 0.21 & 0.977 & $\operatorname{Max}$ & -0.16 & 0.55 & 0.835 \\
\hline $250-450$ & Min & 0.32 & 0.34 & 0.983 & Min & -0.19 & 0.29 & 0.965 \\
\hline $0-500$ & & & 0.32 & 0.966 & & & 0.37 & 0.930 \\
\hline
\end{tabular}

Table 5: Quantitative comparison for Volume Flow at the admission branch between experimental data and the response by the ISIS code with the MLR curve 'MLR-exp' or 'MLR-exp-free-atm' as input.

\begin{tabular}{|c|c|c|c|c|c|c|c|c|}
\hline Q-EXT & \multicolumn{4}{|c|}{$\begin{array}{c}\text { ISIS } \\
\text { MLR-exp }\end{array}$} & \multicolumn{4}{|c|}{$\begin{array}{c}\text { ISIS + Peatross - Beyler } \\
(1 \times 1 \times 0.4) \text { MLR-exp-free- } \\
\text { atm }\end{array}$} \\
\hline $\begin{array}{l}\text { Time } \\
\text { frame } \\
\text { (s) }\end{array}$ & Loca & Error & $\begin{array}{l}\text { Global } \\
\text { Error }\end{array}$ & cosine & Loca & Error & $\begin{array}{c}\text { Global } \\
\text { Error }\end{array}$ & cosine \\
\hline $0-100$ & $\operatorname{Max}$ & -0.01 & 0.13 & 0.993 & Max & -0.03 & 0.11 & 0.995 \\
\hline $100-250$ & $\operatorname{Max}$ & -0.16 & 0.14 & 0.998 & Max & -0.13 & 0.24 & 0.980 \\
\hline $250-450$ & Min & 0.38 & 0.42 & 0.918 & Min & -0.63 & 0.68 & 0.731 \\
\hline $0-500$ & & & 0.24 & 0.972 & & & 0.37 & 0.930 \\
\hline
\end{tabular}

Table 6: Quantitative comparison for Volume Flow at the extraction branch between experimental data and the response by the ISIS code with the MLR curve 'MLR-exp or 'MLR-exp-free-atm' as input.

- CFAST 
The pressure evolution observed for the different simulations shown in Figure 13 confirm that for MLR-exp, the LOL must be set on a low value $(<10 \%$ as found in section 5.1). This seems consistent with impact of the MLR response on the pressure and supports the tracking the MLR-exp curve. Recall that for 'MLR-exp-free-atm' as input, the MLR $R_{m}$ CFAST-free-atm response showed the best results for a LOL of $10 \%$ or $12 \%$. This LOL values are confirmed when regarding the pressure behaviour. Visually, one can discuss which LOL to use, but on the basis of the quantitative comparison (Table 7), it can be concluded that using a LOL of $10 \%$ gives the best prediction of the pressure curve. It is therefore decided to further use a LOL value of $10 \%$ when using 'MLR-exp-free-atm' as input.

In order to validate the admission and extraction boundary condition available in CFAST, the pressure and volume flow rate at the admission and extraction branches of the ventilation network are examined (Figure $15 \mathrm{a}$ and b). Fresh air intake trough the admission is blocked between 30 s and 270 s, showing clearly the inability of CFAST to model reversed flows at admission. Air leaves the fire room mainly through the small gaps under the doors (Figure 14). Because the aeraulic resistance of those gaps does not match the true aeraulic resistance as in the experiments, the pressure and the flow rates cannot be predicted accurately at the same time. The extraction condition in CFAST is not capable of capturing a more intense outflow due to the internal pressure rise. In the experiment, newly fresh air enters in the compartment at about 270 s, due to a pressure evolution in the compartment towards ambient pressure. At this point in time, cold air enters the compartment, which results in a pressure drop. Subsequently, the heat of the fire heats up this air, resulting in a pressure rise. After about 270s, also the flow rates through the gaps under the door are responsible for the pressure prediction. In general, the volume flow rate in and out the compartment through the admission and extraction are badly predicted by CFAST. Additionally, it can clearly be seen that the MLR mainly determines the pressure behaviour and that absolute values for pressures are mostly affected by creating gaps under the doors. A quantitative comparison confirms this statement (Table 8 and Table 9). For CFAST, it is also clear within the quantitative comparison that the prediction is somewhat better for the extraction branch, here certainly due to the inability of CFAST to predict reverse flow. Consequently, it is expected that smoke concentration, interface heights and even temperatures will be affected by this behaviour. It appears that CFAST is able to predict the pressure time curve quite well when compared to ISIS (Table 4 vs. Table 7), and this in order to make safety evaluations related to pressure inside the compartment. The former is true for completely open simulations, but recall that the leakage (gap under the doors) in the CFAST simulation 
was chosen "ad hoc", (even if it seems realistic) so that the calculated pressure resembles the measured pressure. With the measured MLR inside the compartment (e.g. MLR-exp) as input, CFAST was able predict the right shape of the pressure, but absolute values were hard to determine if one does not have any experimental data. Above observation is in contrast with the ISIS code, where no gaps were assumed and the pipe-junction boundary condition was able to predict adequately the pressure inside the compartment (Figure 11). This illustrates the interest of thermodynamic pressure modelling of equation (1) and (4).

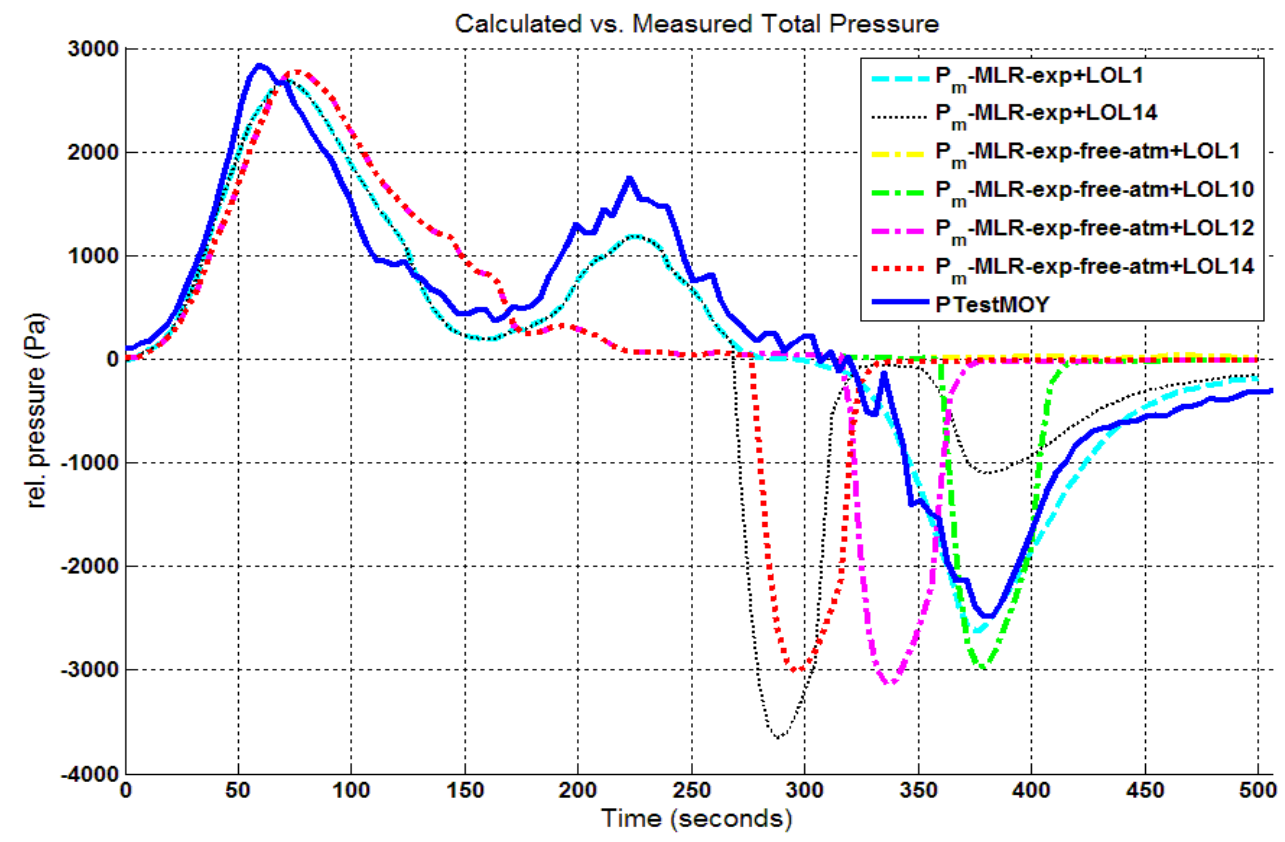

Figure 13: CFAST - Calculated $( \pm 75 \%)$ vs measured $( \pm 2 \%)$ total relative pressure in the fire room (measuring range: $-7000 \ldots 10000 \mathrm{~Pa}$ ). $X_{\mathrm{m}}=$ CFAST prediction 


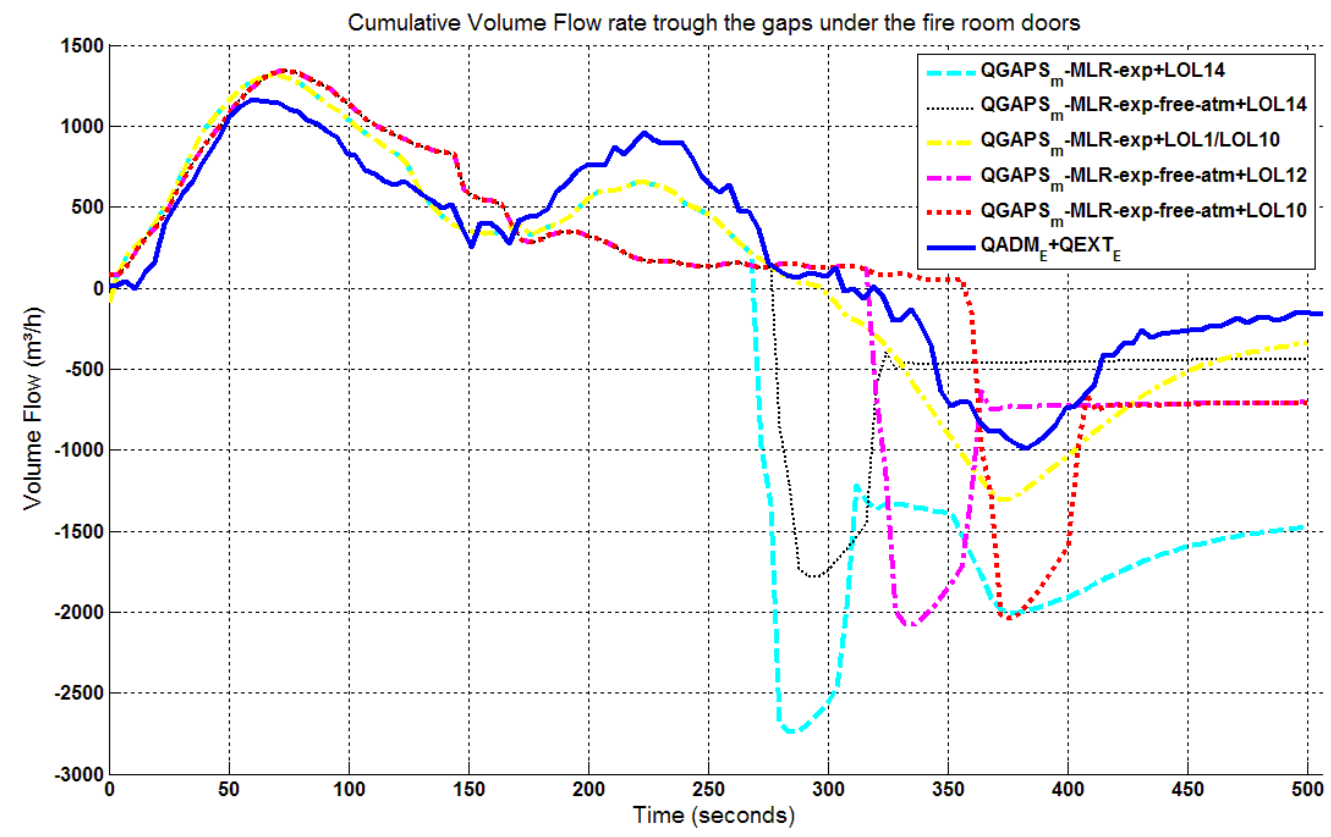

Figure 14: Calculated Volume Flow rate through the 3 gaps under the fire room doors 

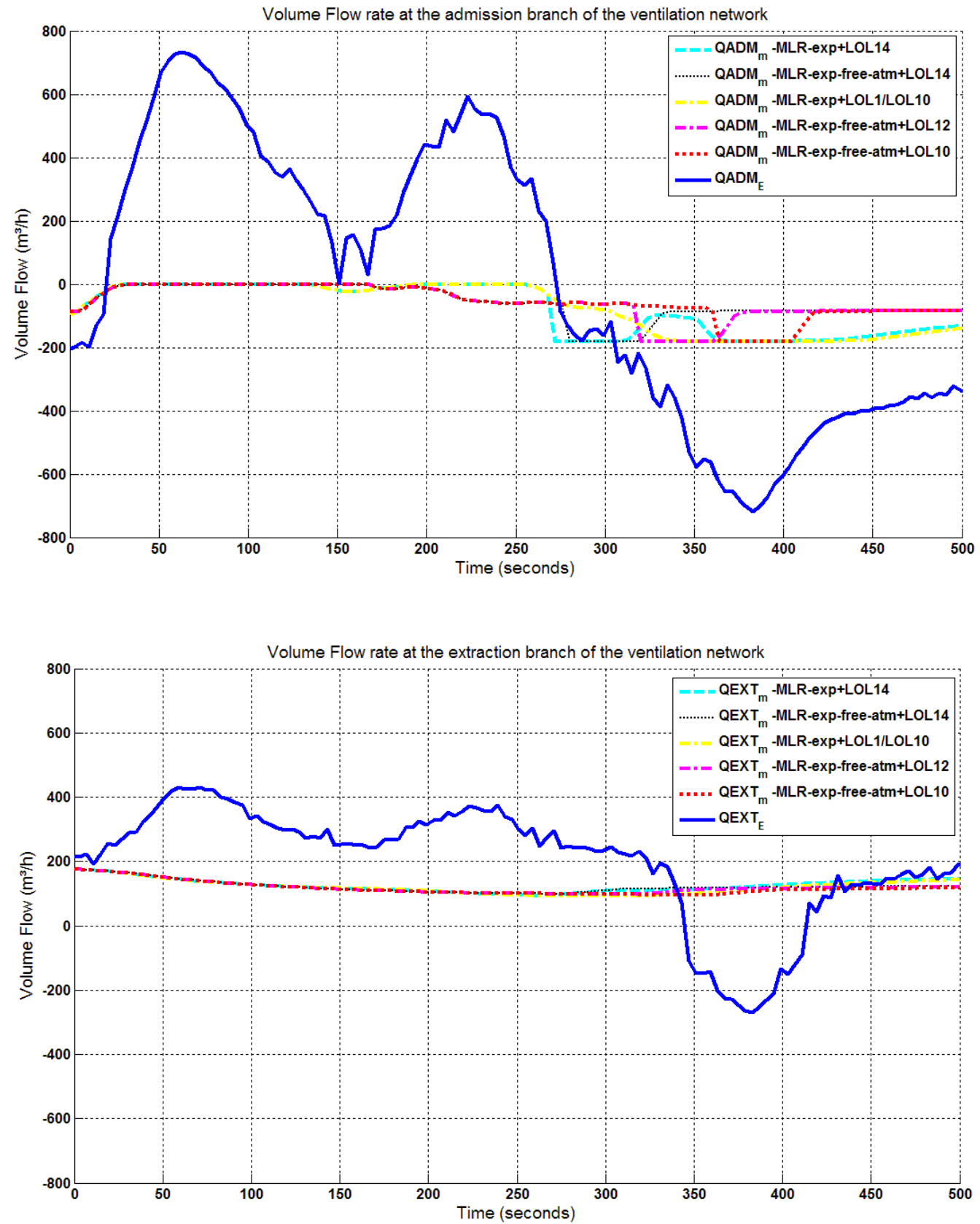

Figure $15 \mathrm{a}$ and $\mathrm{b}$ : Calculated vs. measured ( $\pm 10 \%)$ volume flow rate at the admission (a) and extraction branch (b) of the ventilation network;

$\mathrm{X}_{\mathrm{m}}=$ CFAST prediction; $\mathrm{X}_{\mathrm{E}}=$ experiment.

\begin{tabular}{|l|c|l|l|l|l|l|l|l|l|l|l|l|}
\hline $\begin{array}{l}\text { PRES } \\
\text { SURE }\end{array}$ & \multicolumn{3}{|c|}{ CFAST + LOL 1\% } & \multicolumn{3}{c|}{$\begin{array}{c}\text { CFAST + LOL 10\% } \\
\text { MLR-exp-free-atm }\end{array}$} & \multicolumn{3}{c|}{$\begin{array}{c}\text { CFAST + LOL 12\% } \\
\text { MLR-exp-free-atm }\end{array}$} \\
\hline $\begin{array}{l}\text { Time } \\
\text { frame } \\
(s)\end{array}$ & Local Error & $\begin{array}{c}\text { Global } \\
\text { Error }\end{array}$ & cosine & $\begin{array}{c}\text { Time frame } \\
(s)\end{array}$ & $\begin{array}{c}\text { Local } \\
\text { Error }\end{array}$ & $\begin{array}{c}\text { Global } \\
\text { Error }\end{array}$ & cosine & $\begin{array}{c}\text { Time } \\
\text { frame } \\
(s)\end{array}$ & $\begin{array}{c}\text { Local } \\
\text { Error }\end{array}$ \\
\hline $0-100$ & Max & -0.06 & 0.20 & 0.980 & Max & -0.02 & 0.30 & 0.955 & Max & -0.02 & 0.30 & 0.955 \\
\hline $100-$ & Max & 0.07 & 0.37 & 0.929 & Max & 0.25 & 0.87 & 0.597 & Max & 0.25 & 0.87 & 0.597 \\
\hline
\end{tabular}




\begin{tabular}{|l|l|l|l|l|l|l|l|l|l|l|l|l|}
\hline 250 & & & & & & & & & & & & \\
\hline $\begin{array}{l}250- \\
450\end{array}$ & Min & 0.06 & 0.18 & 0.987 & Min & 0.19 & 0.54 & 0.844 & Min & 0.26 & 1.15 & 0.319 \\
\hline $0-500$ & & & 0.24 & 0.971 & & & 0.56 & 0.834 & & & 0.793 & 0.675 \\
\hline
\end{tabular}

Table 7: Quantitative comparison for PRESSURE between experimental data and the response by the CFAST code with the MLR curve 'MLR-exp' or 'MLR-exp-free-atm' as input.

\begin{tabular}{|l|c|c|c|c|c|c|c|c|c|c|c|c|}
\hline $\begin{array}{c}\text { Q- } \\
\text { ADM }\end{array}$ & \multicolumn{3}{|c|}{$\begin{array}{c}\text { CFAST + LOL 1\% } \\
\text { MLR-exp }\end{array}$} & \multicolumn{3}{c|}{$\begin{array}{c}\text { CFAST + LOL 10\% } \\
\text { MLR-exp-free-atm }\end{array}$} & \multicolumn{3}{c|}{$\begin{array}{c}\text { CFAST + LOL 12\% } \\
\text { MLR-exp-free-atm }\end{array}$} \\
\hline $\begin{array}{l}\text { Time } \\
\text { frame } \\
(s)\end{array}$ & Local Error & $\begin{array}{c}\text { Global } \\
\text { Error }\end{array}$ & cosine & Local Error & $\begin{array}{c}\text { Global } \\
\text { Error }\end{array}$ & cosine & Local Error & $\begin{array}{c}\text { Global } \\
\text { Error }\end{array}$ & cosine \\
\hline $0-100$ & Max & -1.00 & 0.99 & 0.127 & Max & -1.00 & 0.99 & 0.122 & Max & -1.00 & 0.99 & 0.122 \\
\hline $\begin{array}{l}100- \\
250\end{array}$ & Max & -1.00 & 1.01 & -0.217 & Max & -1.00 & 1.06 & -0.761 & Max & -1.00 & 1.06 & -0.761 \\
\hline $\begin{array}{l}250- \\
450\end{array}$ & Min & -0.75 & 0.69 & 0.945 & Min & -0.75 & 0.79 & 0.898 & Min & -0.75 & 0.85 & 0.685 \\
\hline $0-500$ & & & 0.85 & 0.668 & & & 0.91 & 0.561 & & & 0.92 & 0.524 \\
\hline
\end{tabular}

Table 8: Quantitative comparison for Volume Flow at the admission branch between experimental data and the response by the CFAST code with the MLR curve MLR-exp' or 'MLR-exp-free-atm' as input.

\begin{tabular}{|c|c|c|c|c|c|c|c|c|c|c|c|c|}
\hline $\begin{array}{l}\text { Q- } \\
\text { EXT }\end{array}$ & \multicolumn{4}{|c|}{$\begin{array}{c}\text { CFAST + LOL 1\% } \\
\text { MLR-exp }\end{array}$} & \multicolumn{4}{|c|}{$\begin{array}{l}\text { CFAST + LOL 10\% } \\
\text { MLR-exp-free-atm }\end{array}$} & \multicolumn{4}{|c|}{$\begin{array}{l}\text { CFAST + LOL } 12 \% \\
\text { MLR-exp-free-atm }\end{array}$} \\
\hline $\begin{array}{l}\text { Time } \\
\text { frame } \\
\text { (s) }\end{array}$ & LOC & Error & $\begin{array}{l}\text { Global } \\
\text { Error }\end{array}$ & cosine & LOC & I Error & $\begin{array}{l}\text { Global } \\
\text { Error }\end{array}$ & cosine & Loca & Error & $\begin{array}{l}\text { Global } \\
\text { Error }\end{array}$ & cosine \\
\hline $0-100$ & Max & -0.59 & 0.60 & 0.951 & $\operatorname{Max}$ & -0.59 & 0.60 & 0.952 & Max & -0.59 & 0.60 & 0.952 \\
\hline $\begin{array}{l}100- \\
250\end{array}$ & $\operatorname{Max}$ & -0.66 & 0.64 & 0.982 & $\operatorname{Max}$ & -0.66 & 0.65 & 0.985 & Max & -0.66 & 0.65 & 0.985 \\
\hline $\begin{array}{l}250- \\
450\end{array}$ & Min & -1.34 & 1.00 & 0.255 & Min & -1.35 & 0.98 & 0.296 & Min & -1.37 & 1.00 & 0.279 \\
\hline $0-500$ & & & 0.72 & 0.758 & & & 0.71 & 0.777 & & & 0.72 & 0.760 \\
\hline
\end{tabular}

Table 9: Quantitative comparison for Volume Flow at the extraction branch between experimental data and the response by the CFAST code with the MLR curve MLR-exp' or 'MLR-exp-free-atm' as input.

\subsection{Oxygen concentration}

Oxygen concentration is not an important attribute for nuclear fire safety analysis "as such", but it is essentially important as it may influence the outcome of fires in nuclear facilities because of their compartmentalized nature. Oxygen has a direct influence on the burning behaviour of a fire, especially if the concentration is relatively low (see section 5.1). The CFAST two-zone model is able to predict oxygen concentration in 
the upper and lower layers, and the ISIS model calculates the oxygen concentration in each control volume defined in the computational domain.

- ISIS

Figure 16 depicts the measured versus predicted oxygen volume concentrations in time by ISIS. The measured oxygen concentration has an expanded uncertainty of \pm $2 \%$ [14]. ISIS predicts the oxygen concentration very well in the high region (HAUT) and the region close to the flame base (FP), no matter if the input is 'MLR-exp' or 'MLR-exp-free-atm' (Table 10). In the lower region, outside the flame region (BAS), the oxygen concentration drops sooner in the experiments, likewise as observed in the high region. This behaviour is not captured correctly by the ISIS code. Nevertheless, minimum oxygen concentration and oxygen rise after extinction is well captured.
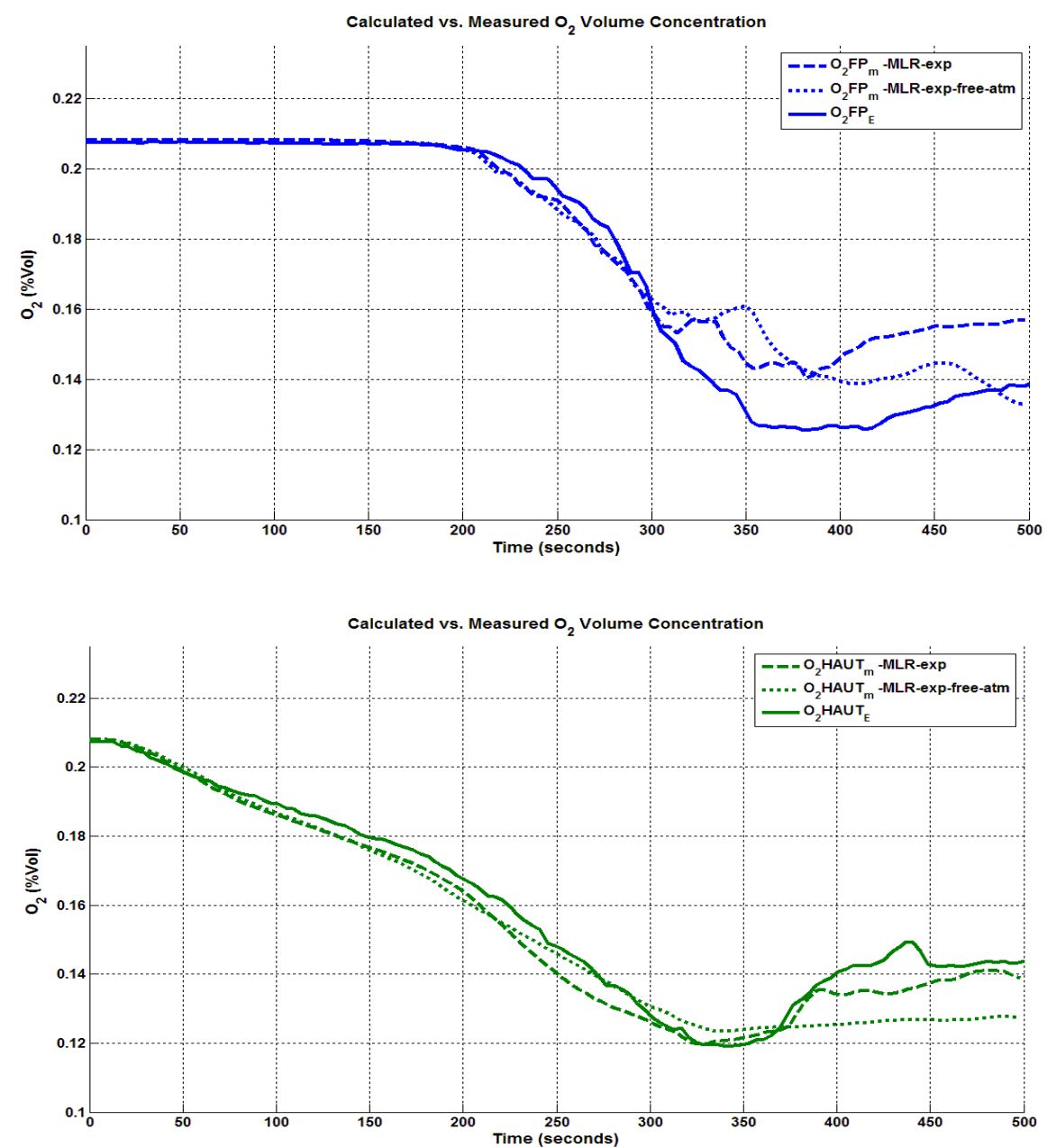


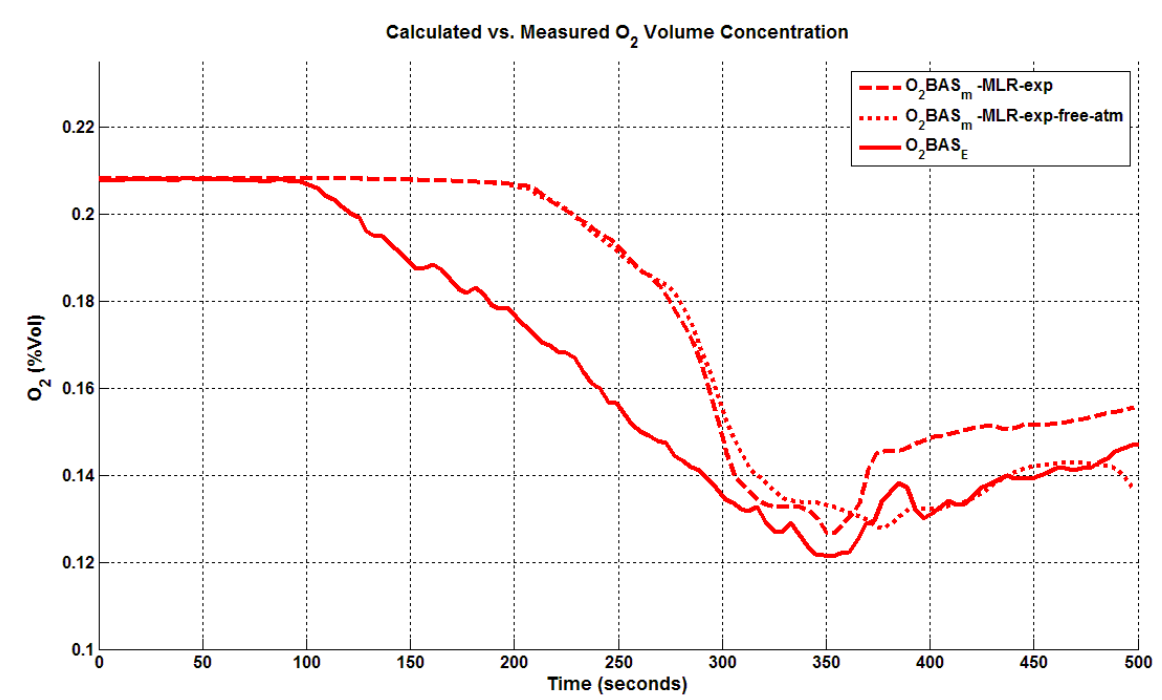

Figure 16 a - c: Calculated $( \pm 8 \%)$ vs. Measured $( \pm 1 \%) O_{2}$ Volume concentration for the sensors (a) $\mathrm{O}_{2} \mathrm{FP}\left(\mathrm{Z}=0.35 \mathrm{~m}\right.$ : $\left.x \_\mathrm{NS}=-0.8 \mathrm{~m} ; \mathrm{x} \_\mathrm{EW}=0\right)$,

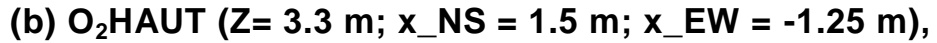

(c) $\mathrm{O}_{2} \mathrm{BAS}\left(\mathrm{Z}=0.8 \mathrm{~m}\right.$; $\mathrm{x} \_\mathrm{NS}=1.5 \mathrm{~m} ; \mathrm{x} \_\mathrm{EW}=-1.25 \mathrm{~m}$ );

$X_{m}=$ ISIS prediction, $X_{E}=$ experiment.

\begin{tabular}{|c|c|c|c|c|c|c|}
\hline $\mathrm{O}_{2}$ & & $\begin{array}{c}\text { ISIS } \\
\text { MLR-exp }\end{array}$ & & $\begin{array}{r}\text { ISIS } \\
\text { Beyle } \\
\text { e }\end{array}$ & $\begin{array}{l}+ \text { Peatr } \\
(1 \times 1 \times 0 . \\
\text { p-free-a }\end{array}$ & $\begin{array}{l}\text { SS - } \\
\text { MLR- } \\
\text { m }\end{array}$ \\
\hline $\begin{array}{l}\text { Time } \\
\text { frame } 0 \text { - } \\
500 \text { s }\end{array}$ & $\begin{array}{l}\text { Local } \\
\text { Error }\end{array}$ & $\begin{array}{c}\text { Global } \\
\text { Error }\end{array}$ & cosine & $\begin{array}{l}\text { Local } \\
\text { Error }\end{array}$ & $\begin{array}{c}\text { Global } \\
\text { Error }\end{array}$ & cosine \\
\hline FP & 0.12 & 0.06 & 0.998 & 0.06 & 0.05 & 0.999 \\
\hline HAUT & 0.00 & 0.03 & 1.000 & 0.04 & 0.05 & 0.999 \\
\hline BAS & 0.04 & 0.11 & 0.998 & 0.05 & 0.10 & 0.997 \\
\hline
\end{tabular}

Table 10: Quantitative comparison for oxygen volume concentration between experimental data and the response by the ISIS code with 'MLR-exp' or 'MLR-exp-freeatm' as input.

Figure 17 depicts two sectional planes which visualise the oxygen mass fraction for the MLR-exp simulation (see Figure 3). The higher oxygen region (red) can be expected to dictate the oxidation of fuel (thus the burning). For this reason, a higher oxygen region around the burner with an area $1 \mathrm{~m}^{2}$ and $0.4 \mathrm{~m}$ height was then "ad hoc" chosen as bounding area for averaging the oxygen molar fraction $\mathrm{X}_{\mathrm{O} 2}$ when using the 'MLR-exp-free-atm', i.e. as measured in the free atmosphere as an input (see section 5.1). The oxygen reduction via the Peatross \& Beyler correlation resulted subsequently in the MLR-exp-free-atm response. 

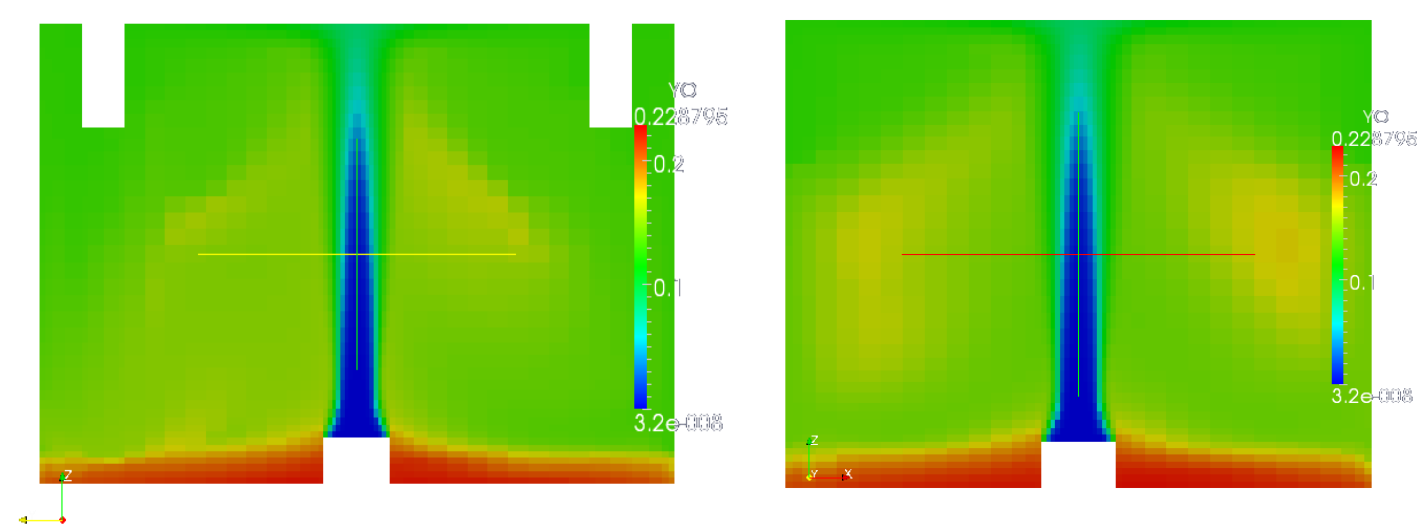

Figure 17: Visualisation of the oxygen mass fraction at $t=315 \mathrm{~s}$; $Y O$ in $\%$ (plane left: $\mathrm{x} \_E W=0 \mathrm{~m}$; plane right: $\mathrm{x}_{-} \mathrm{NS}=0 \mathrm{~m}$ )

\section{- CFAST}

For completeness, the Figure 18 depicts the result of predicted oxygen volume concentration obtained by CFAST. Because of the two-zone principle of CFAST and the fact that the upper layer descends very rapidly under $0.8 \mathrm{~m}$, the sensor at the bottom ("BAS") is not shown on the figure. As could be expected by the inability to capture reverse (in)flow in CFAST (Figure 15), the oxygen concentration is somewhat underestimated: less fresh air enters the compartment in the simulations, compared to the experiments.

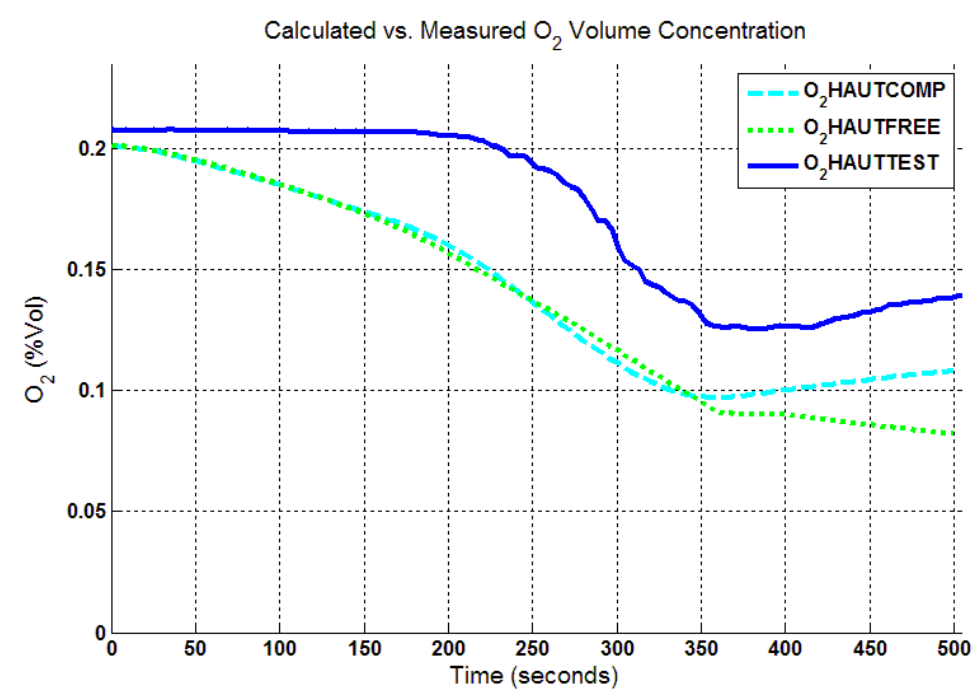

Figure 18: Calculated $( \pm 8 \%)$ vs. Measured $( \pm 1 \%) \mathrm{O}_{2}$ Volume concentration for the sensor $\mathrm{O}_{2}$ HAUT $\left(Z=3.3 \mathrm{~m}\right.$; $x_{-} \mathrm{NS}=1.5 \mathrm{~m}$; $\left.x_{-} E W=-1.25 \mathrm{~m}\right)$.

In addition, Table 11 provides the quantitative comparison for oxygen volume concentration between experimental data and the response by the CFAST code with the MLR curve 'MLR-exp' or 'MLR-exp-free-atm' as input.

\begin{tabular}{|c|c|c|}
\hline $\mathrm{O}_{2}$ & CFAST + LOL 1\% & CFAST + LOL 10\% \\
\hline
\end{tabular}




\begin{tabular}{|l|c|c|c|c|c|c|}
\hline & \multicolumn{3}{|c|}{ MLR-exp } & \multicolumn{3}{c|}{ MLR-exp-free-atm } \\
\hline $\begin{array}{l}\text { Time } \\
\text { frame 0 - } \\
\text { 500s }\end{array}$ & Eocal & Global & cosine & Local & Global & cosine \\
Error & & Error & Error & \\
\hline HAUT & -0.22 & 0.20 & 0.994 & -0.34 & 0.22 & 0.992 \\
\hline
\end{tabular}

Table 11: Quantitative comparison for oxygen volume concentration between test data and the response by the CFAST code with the 'MLR-exp' or 'MLR-exp-free-atm' as input.

\section{$6 \quad$ Extra Numerical ISIS experiments: sensitivity analysis}

The following sensitivity study is based on the input settings as described in paragraph 3.2 and only for MLR-exp. The simulation results of this reference case are shown in paragraph 5.

\subsection{Overview of the sensitivity performed}

\subsubsection{Soot production (ISIS)}

Soot is a product of incomplete combustion and its formation is a complex phenomenon, making it difficult to model. Nevertheless, soot is of importance in thermal radiation models. Many approaches are available, but only two are restrained.

\section{- Fixed soot yield fraction}

The reference simulation was set up with a fixed soot yield fraction ys of 0.11 . This value of soot fraction was based on the average of the soot measurement values for the experiment. For a first sensitivity study, this fixed soot yield was set to 0.15 [11] and the stoichiometric carbon coefficient of the dodecane combustion was consequently changed. This higher value of soot fraction is set on the assumption that quite some soot will be formed during the burning period. Due to this consideration, a value of 0.15 would possible be used when considering this scenario for safety analysis purposes.

Simulation IDs: M6_ys0.15_FVM ${ }^{1}$ vs. M6_ys011_FVM.

\section{- Modeling soot yield}

\footnotetext{
${ }^{1}$ This code means: mesh size and time step 'M6', ys $=0.15$ and using FVM to calculate the radiative heat transfer
} 
The Moss two-equation model is used to model the soot production [18]. The variables of the modal are:

- the soot mass fraction Ys,

- the soot particle concentration $\mathrm{Xn}$ [mol.kg-1].

This model takes into account the processes of nucleation, surface growth and coagulation. The soot combustion term depends on a specific oxidation rate.

Moreover, a thermodiffusion is added to the equations.

The use of this model can be compared to the use of fixed soot yield modelling as described above. Two sets of Moss-coefficients, which depend on the fuel, were used ( $\mathrm{C} \alpha, \mathrm{C} \beta$ and $\mathrm{C}$ ); ; one set for Low Sooty (LS) flames and one set of Heavy Sooty (HS) flames. The model constants used were ([18] and [19]):

LS: $C_{\alpha}=1.7 \times 10^{8} \mathrm{~m}^{3} \mathrm{~kg}^{-2} \mathrm{~K}^{-1 / 2} \mathrm{~s}^{-1} ; \mathrm{C}_{\beta}=1.0 \times 10^{9} \mathrm{~m}^{3} \mathrm{~K}^{-1 / 2} \mathrm{~s}^{-1} ;$ and $\mathrm{C}_{\mathrm{y}}=4.2 \times 10^{-17} \mathrm{~kg}^{-2 / 3} \mathrm{~K}^{-}$ ${ }^{1 / 2} S^{-1}$

HS: $\mathrm{C}_{\alpha}=1.3 \times 10^{6} \mathrm{~m}^{3} \mathrm{~kg}^{-2} \mathrm{~K}^{-1 / 2} \mathrm{~s}^{-1} ; \mathrm{C}_{\beta}=2.0 \times 10^{9} \mathrm{~m}^{3} \mathrm{~K}^{-1 / 2} \mathrm{~s}^{-1} ;$ and $\mathrm{C}_{\mathrm{Y}}=8.5 \times 10^{-13} \mathrm{~kg}^{-2 / 3} \mathrm{~K}^{-}$ ${ }^{1 / 2} S^{-1}$

For both simulations, the fuel is treated as dodecane incomplete combustion in air as presented in paragraph 3.2.

Simulation IDs: M6_mossLS_FVM vs. M6_mossHS_FVM (vs. M6_ys0.15_FVM \& M6_ys011_FVM)

\subsubsection{Radiation modelling}

- P1 vs. FVM

Using the P1 radiation model instead of the Finite Volume Method (FVM) is considered [18]. Within the spherical harmonic approximation $\mathrm{P} 1$, radiation intensity is expressed by means of 1 harmonic, while with FVM the total set of admissible directions of propagation is discretized in a finite set of control angles characterize by the angular coordinates of its direction. The P1 approximation is very accurate if the optical dimension of the medium is large. However, it yields inaccurate results for thinner media particular near the domain boundaries.

Simulation IDs: M6_ys0.11_P1 vs. M6_ys011_FVM

\subsubsection{Wall emissivity}

The emissivity of the wall is changed from 0.9 (soot deposits) to 0.7 (no soot deposits). Simulation IDs: M6_ys0.11_FVM vs. M6_ys011_FVM_Ew07

\subsubsection{Turbulence modelling}


Two-equation turbulence RANS models ( $k-\varepsilon$ and $k-\varepsilon R N G$ ) with buoyancy modifications of the source terms can be employed in ISIS to predict turbulent viscosity, characteristic length and time scale [18]. With RNG, the transport k-equation remains the same as the standard $\mathrm{k}-\varepsilon$ model except for model constant.

Nevertheless, a modification to the $\varepsilon$ equations is made, whereby an additional rate of strain term is introduced. For weakly to moderate strained flows, the RNG $k-\varepsilon$ model tends to yield comparable results to the $k-\varepsilon$ model. No rapid strain or streamline curvature is expected, so results should be largely equal.

Simulation IDs: M6_ys0.11_FVM vs. M6_ys011_FVM_RNG

\subsubsection{In- and output branch flow resistance}

The pipe-junction boundary condition implemented in ISIS is intended to be applied in the case of a confined domain which is connected to a ventilation network (1). The sensitivity consists of changing the aeraulic resistance $\mathrm{R}$ of the network in order to investigate the effects on the pressure. $R$ is changed to $1.1 R(+10 \%)$ to study the behaviour for a larger flow resistance. The resistance is also changed to $-10 \%,-30 \%$ and $-50 \%$ in order to investigate the behaviour when applying a more open boundary condition.

Simulation IDs: M6_ys0.11_FVM_R+10\%, M6_ys0.11_FVM_R-10\%, M6_ys0.11_FVM_R-30\%, M6_ys0.11_FVM_R-50\% vs. M6_ys0.11_FVM

\subsection{Results of the sensitivity study}

With the use of the pipe-junction boundary condition, the pressure inside the compartment during a fire is adequately predicted. This boundary condition relies on measured pressures, but only at steady state before ignition. Consequently, semi-blind simulation can be made with some degree of confidence in pressure predictions.

Figure 19 and Figure 20 show the sensitivity analysis results for the pressure predictions in the compartment. 


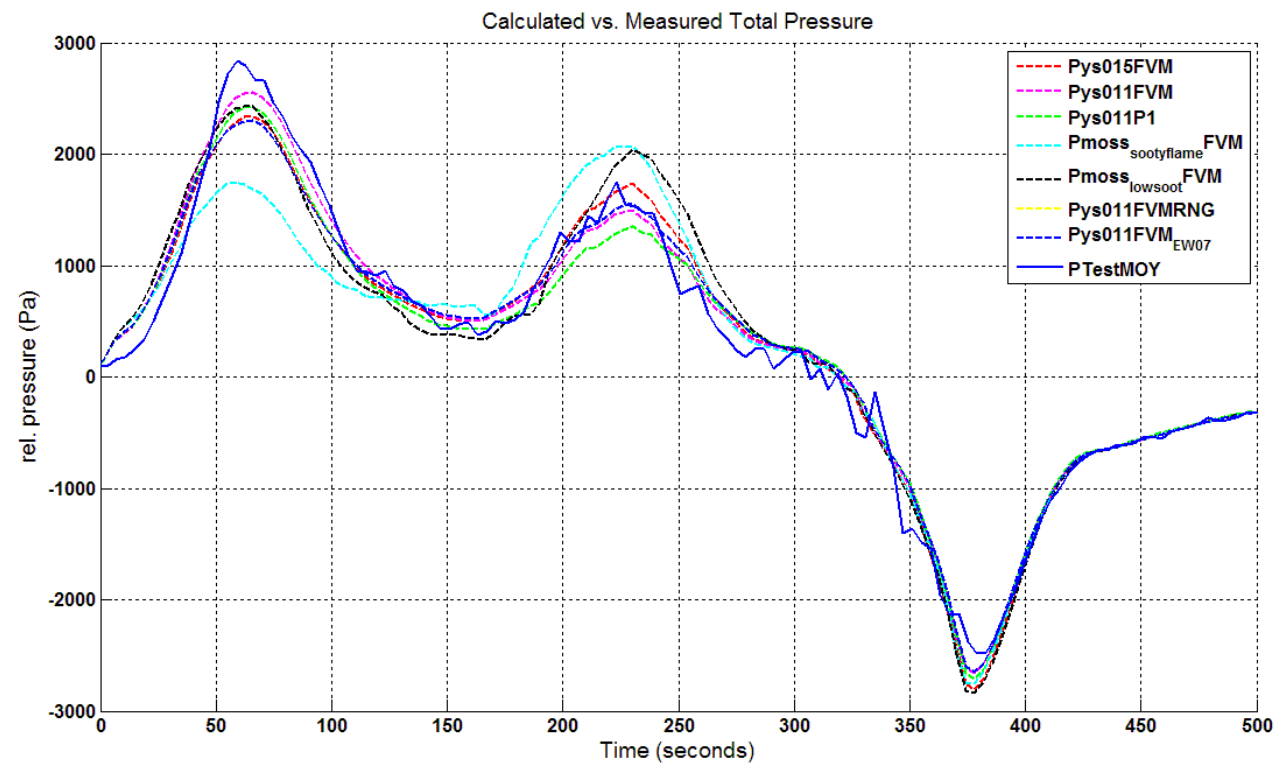

Figure 19: Plot of Calculated vs. Measured Total Pressure sen sitivity.

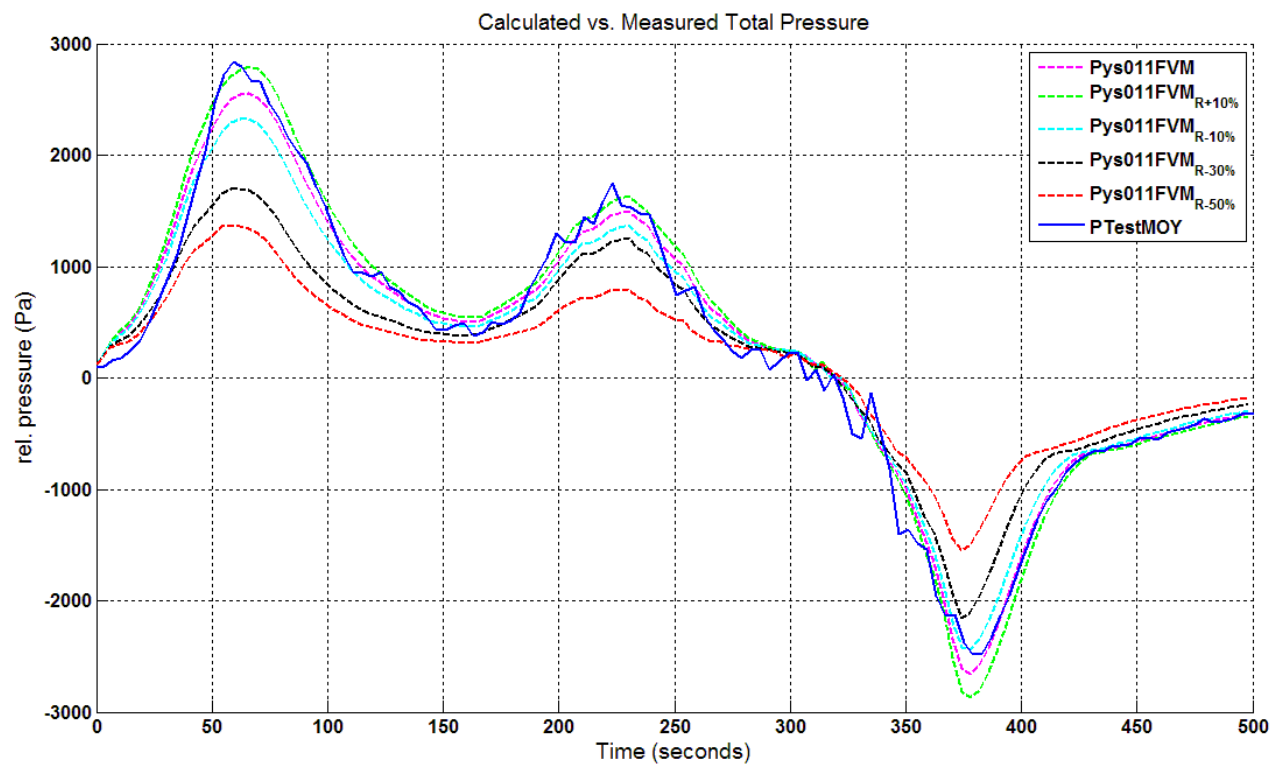

Figure 20: Plot of Calculated vs. Measured Total Pressure sensitivity for change in- and outflow branch resistance.

These pressure responses are subsequently investigated through the use of the metrics proposed in paragraph 4.

Figure 21 depicts the evolution in Global Error for the conducted sensitivity. It can be concluded that the aeraulic resistance has the largest influence on the pressure results. Because aeraulic resistance is calculated from pressure measurements, it constitutes an error input for simulations. It is observed that an uncertainty of $10 \%$ on the aeraulic resistance is acceptable for conducting simulations. Using open boundary conditions for modelling the aeraulics seems unacceptable as from lowering the 
resistance with $30 \%$, the Global Error becomes larger than $30 \%$. Further, it is observed that soot modelling has a relatively strong influence on the Global Error and is the only parameter which greatly affects the shape of the pressure curve (Figure 22). The soot yield fraction strongly determines the soot concentration, which in turn affects the radiation heat transfer and subsequently gas and wall temperatures [20]. This explains changes in the pressure variation (through the ideal gas law). Preferably, a fixed soot yield ys of 0.11 (mean value as measured during the experiment) is used. Nevertheless, using the Moss-model to predict soot yield with low soot (LS) model constants is useful and acceptable in an error range of $25 \%$.

The results are less sensitive to changes in other model settings. The relative importance of changing the radiation model, wall emissivity and turbulence modelling can be seen in Figure 23 to Figure 25. Wall emissivity and radiation modelling affect gas and wall temperatures [20], and thus subsequently the pressure evolution inside the compartment. Using P1 approximation to solve the radiation or FVM does not change Local Error for pressure predictions, even so as using the RNG $k-\varepsilon$ model instead of the unaltered $\varepsilon$ equation. The third most important parameter seems thus to be the wall emissivity. At the beginning of the fire, there are minor soot deposits on the wall, such that an emissivity of 0.7 is more acceptable to use. As the fire starts to extinguish, a wall emissivity of 0.9 seems more appropriate as can be seen by a lower Local Error in pressure predictions after 250s.

Euclidean Pressure Global Error

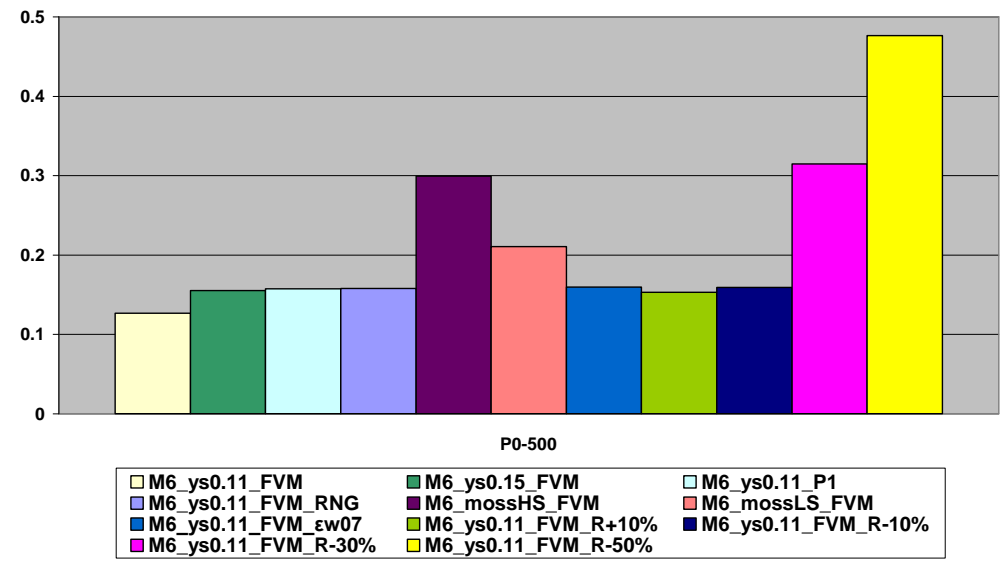

Figure 21: Quantitative comparison via Global Error of pressure sensitivity response (0-500s). 
Euclidean Pressure cosine

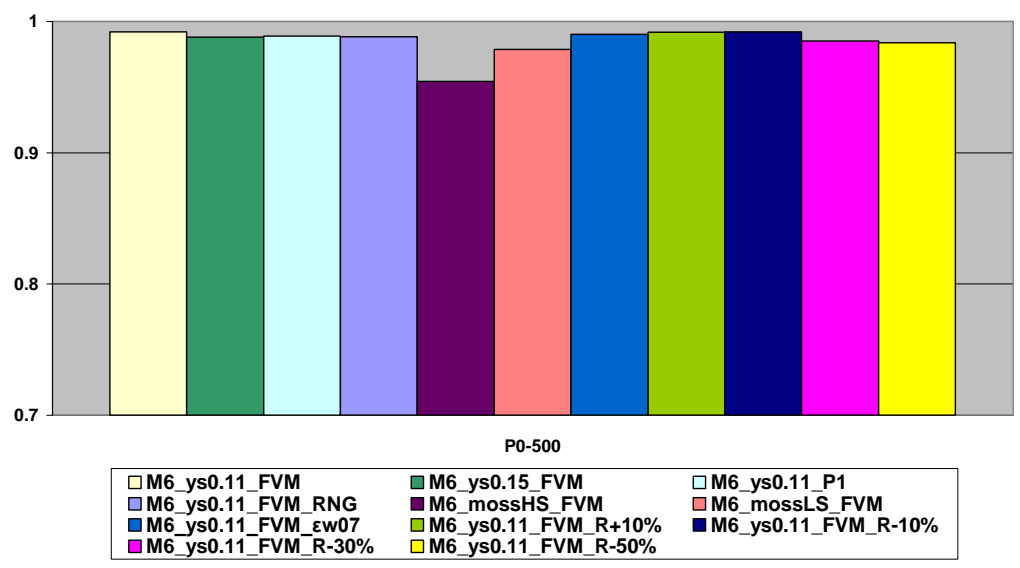

Figure 22: Quantitative comparison via Cosine of pressure sensitivity response (0-500s).

Pressure Local Error Maximum

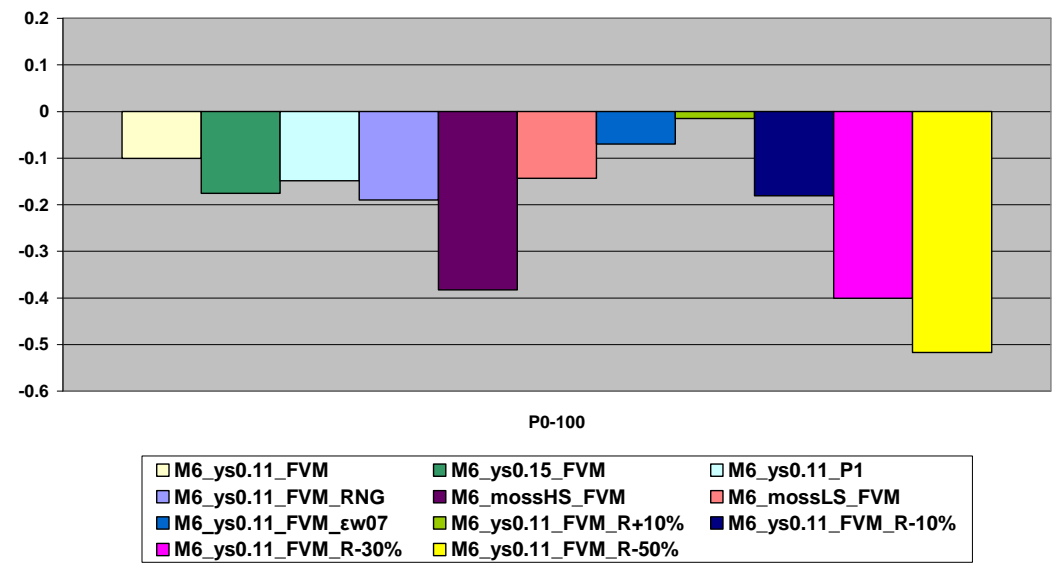

Figure 23: Quantitative comparison via Local Error of maximum pressure sensitivity response between 0 and 100s (first pressure peak).

Pressure Local Error Maximum

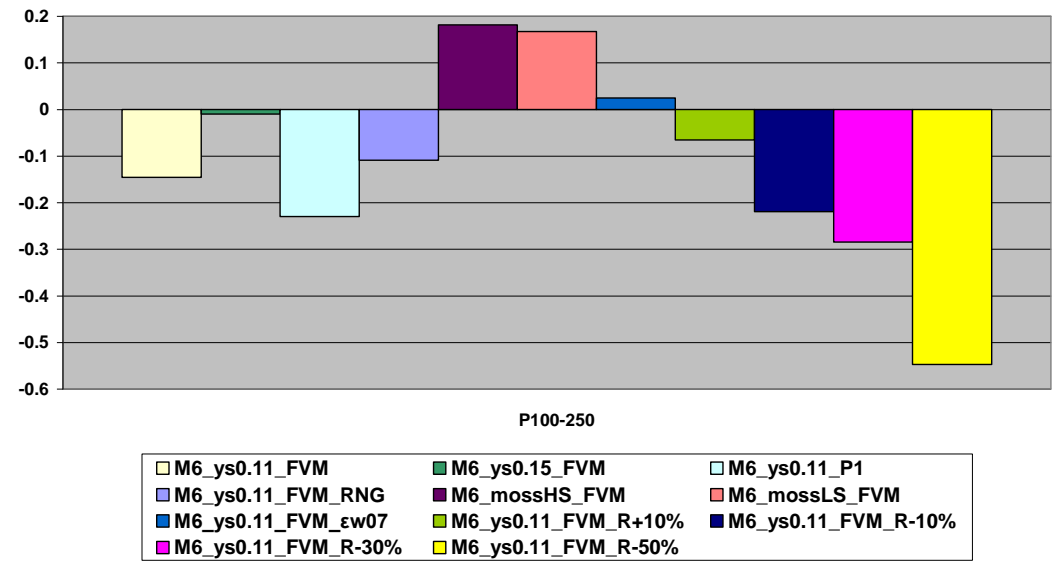

Figure 24: Quantitative comparison via Local Error of maximum pressure sensitivity response between 100 s and 250 s (second pressure peak). 


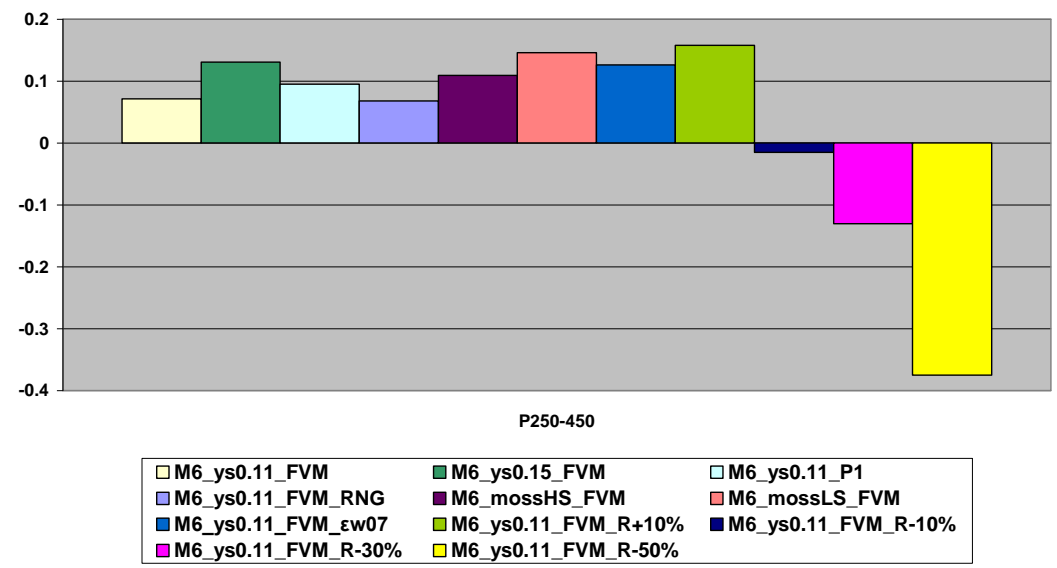

Figure 25: Quantitative comparison via Local Error of maximum pressure sensitivity response between 250 and 450 s (pressure pit).

\section{$7 \quad$ Conclusions and outlook}

The main objective of this work was to study the capability of a zone model (CFAST) and a field model (ISIS) to predict the interaction between mass loss rate and total relative room pressure. The reproduction of pressure variations is important for the nuclear safety. Room pressure variations are indeed from interest when dealing with dynamic confinement to prevent radioactive releases in nuclear facilities or when contributing to smoke propagation to adjacent rooms. It appears that the mass loss rate strongly affects the pressure behaviour inside the compartment. The two models used are able to predict the pressure time curve quite well both when imposing the MLR measured during the experiments or the MLR determined in a free atmosphere. However, it has to be pointed out that leakages in the zone model CFAST have been chosen such that the calculated pressure resembles the measured pressure (even if the leakage values seem realistic). Doing this, CFAST is able to reproduce the experimental pressure and is a useful tool to conduct sensitivity studies. Nevertheless, it is not recommended for blind simulations for the test case at hand, since then absolute pressure levels results will be uncertain. With the zone model ISIS, on the other hand, the pressure behaviour is predicted well, illustrating the interest of thermodynamic pressure modeling.

The performed simulations have also showed the importance to consider the extinction phase of a fire within safety analyses concerning pressure confinements.

The influence of mass loss rate on oxygen concentration has also been analyzed within this work. Oxygen concentration has a direct influence on the burning behaviour of a fire. It appears that the field model (ISIS) predicts very well the oxygen 
concentration both with the MLR measured during the experiments or the MLR determined in a free atmosphere. On the other hand, the simulations performed with the two-zone model (CFAST) showed limitations to predict the oxygen concentration due to the inability to capture reverse flow.

To complete this work a sensitivity study has been performed for the field model. Influence on the outputs of soot production, radiation modelling, wall emissivity, turbulence modelling and branch flow resistance have been analyzed. The aeraulic resistance is the most important parameter. The model for soot also has a relatively strong influence, through the impact on the evolution of the temperature inside the compartment. Further investigations on the influence of soot models would therefore be interesting. In the same sense, heat losses from the compartment (and e.g. wall emissivities) are also important issues to consider.

[1] ISO 17873, Nuclear facilities - Criteria for the design and operation of ventilation systems for nuclear installations other than reactors, 1 st edition (2004).

[2] Prétrel, H. and J.M. Such, Study based on large-scale experiments on the periodic instabilities of pressure and burning rate in the event of pool fire in a confined and mechanically ventilated compartment, Third European Combustion Meeting ECM (2007).

[3] W. P. Jones, R. D. Peacock, G. P. Forney, P. A. Reneke, CFAST - Consolidated Model of Fire Growth and Smoke transport (version 6) - Technical reference guide, Technical Report NIST-SP-1026, National Institute of Standards and Technology (Revision April 2009).

[4] Institut de Radioprotection et de Sûreté Nucléaire, ISIS 2.3.1 - Tutorial, Validation and Verification, IRSN Publications (2011).

[5] Laurent Adouin, Hugues Prétrel, William Le Saux, Overview of the OECD PRISME PROJECT - Main Experimental Results, 21th International Conference on Structural Mechanics in Reactor Technology (SMiRT 21), 2011

[6] Prétrel, H., Querre, P. and Forestier, M., (2005). Experimental Study Of Burning Rate Behaviour In Confined And Ventilated Fire Compartments. Fire Safety Science 8: 1217-1228. doi:10.3801/IAFSS.FSS.8-1217.

[7] McCaffrey, B.J., "Momentum Implications for Buoyant Diffusion Flames," Combustion and Flame 52, 149 (1983).

[8] SGDH - single gradient diffusion hypothesis in K. Van Maele and B. Merci, "Application of Two BuoyancyModified k- $\varepsilon$ Turbulence Models to Different Types of Buoyant Plumes", Fire Safety Journal, Vol. 41 (2), pp. 122-138 (2006)

[9] Institut de Radioprotection et de Sûreté Nucléaire, Resolution in ISIS of the Radiative Transfer Equation using the Finite Volume Method, SEMIC-(2010)-067/DL Ind.1.

[10] V. Novozhilov. Computational fluid dynamics modeling of compartment fires. Progress in Energy and Combustion Science, 27:611-666 (2001).

[11] Archibald Tewarson, Chapter 4 in The SFPE Handbook of Fire Protection Engineering, 3th Edition (2002).

[12] Yeoh, G.H and K.K. Yuen, Computational fluid dynamics in fire engineering: theory, modelling and practice. Amsterdam: Elsevier. ISBN 978-0-7506-8589-4 (2009).

[13] Sam S.Y. Wang, Patrick J. Roche, Richard A. Schmals, Yafei Jia and Peter E. Smith, Verification and Validation of 3D Free-surface Flow Models, ASCE ISBN 978-0-7844-0957-2. (2008).

[14] L. Audouin et.al., Quantifying differences between computational results and measurements in the case of a large-scale well-confined fire scenario. Nuclear Engineering and Design 241 (2011). 
[15] Verification and Validation of Selected Fire Models for Nuclear Power Plant Applications, Technical Report NUREG-1824 and EPRI 1011999, U.S. Nuclear Regulatory Commission, Office of Nuclear Research (RES), Rockville, MD, 2007, and Electric Power Institute (EPRI), Palo Alto, CA. (2007).

[16] Peatross, M. J. and Beyler, C. L., "Ventilation effects on compartment fire characterization", Fire Safety Science - Proceeding of the Fifth International Symposium, International Association for Fire Safety Science, (1997), pp 403414.

[17] S. Suard, A. Nasr, S. Mélis, J-P Garo, H. EL-Rabii, L. Gay and L. Audouin, Analytical Approach for Predicting Effects of Vitiated Air on the Mass Loss Rate of Large Pool Fire in Confined Compartments, Fire Safety Science 10 IAFSS, (2011).

[18] Institut de Radioprotection et de Sûreté Nucléaire, ISIS 2.3.1 - Physical Modelling, IRSN Publication (2011).

[19] Guan heng Yeoh, Kwok Kit Yuen, Computational Fluid Dynamics in Fire Engineering, Theory, Modelling and Practice, ELSEVIER. ISBN 978-0-7506-8589-4. (2009).

[20] Sylvain Suard, Sylvain Vaux and Laurence Rigollet, Fire Code Benchmark activities within the international research project PRISME - discussion on metrics used for validation and on sensitivity analysis, SMirt 21, 2011 